\title{
Hybrid Noble-Metals/Metal-Oxide Bifunctional Nano- Heterostructure Displaying Outperforming Gas-Sensing and Photochromic Performances
}

\author{
David Maria Tobaldi, ${ }^{*} \dagger$ Salvatore Gianluca Leonardi, ${ }^{\ddagger}$ Kaveh Movlaee, ${ }^{\ddagger}, \S$ Luc Lajaunie, \\ Maria Paula Seabra, ${ }^{\dagger}$ Raul Arenal, ${ }^{\|, \perp}{ }^{\circ}$ Giovanni Neri, ${ }^{\ddagger}$ and João António Labrincha ${ }^{\dagger}$ \\ ${ }^{\dagger}$ Department of Materials and Ceramics Engineering/CICECO-Aveiro Institute of Materials, University of Aveiro, Campus \\ Universitário de Santiago, 3810-193 Aveiro, Portugal \\ ${ }^{\ddagger}$ Department of Engineering, University of Messina, C.da Di Dio, 98166 Messina, Italy \\ ${ }^{\S}$ Center of Excellence in Electrochemistry, School of Chemistry, College of Science, University of Tehran, 14155-6455 Tehran, Iran \\ "Laboratorio de Microscopías Avanzadas, Instituto de Nanociencia de Aragón, Universidad de Zaragoza, 50018 Zaragoza, Spain \\ ${ }^{\perp}$ ARAID Foundation, 50018 Zaragoza, Spain
}

Supporting Information

\begin{abstract}
As nanomaterials are dominating 21st century's scene, multiple functionality in a single (nano)structure is becoming very appealing. Inspired by the Land of the Rising Sun, we designed a bifunctional (gas-sensor/photochromic) nanomaterial, made with $\mathrm{TiO}_{2}$ whose surface was simultaneously decorated with copper and silver (the $\mathrm{Cu} / \mathrm{Ag}$ molar ratio being 3:1). This nanomaterial outperformed previous state-of-the-art $\mathrm{TiO}_{2}$-based sensors for the detection of acetone, as well as the $\mathrm{Cu}-\mathrm{TiO}_{2}$-based photochromic material. It indeed possessed splendid sensitivity toward acetone (detection limit of $100 \mathrm{ppb}, 5$ times lower than previous state-of-the-art $\mathrm{TiO}_{2}$-based acetone sensors), as well as reduced response/recovery times at very low working temperature, $150{ }^{\circ} \mathrm{C}$, for acetone sensing. Still, the same material showed itself to be able to (reversibly) change in color when stimulated by both UV-A and, most

One part of silver plus three parts of copper to decorate $\mathrm{TiO}_{2} \mathrm{NPS}$

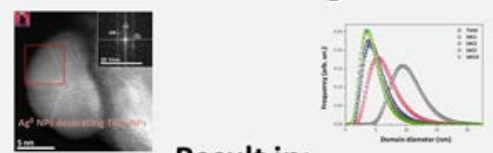

Result in:

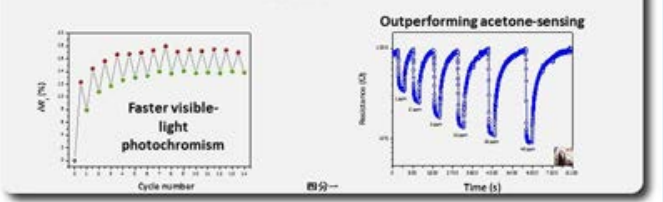
remarkably, visible light. Indeed, the visible-light photochromic performance was almost 3 times faster compared to the standard $\mathrm{Cu}-\mathrm{TiO}_{2}$ photochromic material一that is, $4.0 \mathrm{~min}$ versus $10.8 \mathrm{~min}$, respectively. It was eventually proposed that the photochromic behavior was triggered by different mechanisms, depending on the light source used.
\end{abstract}

\section{INTRODUCTION}

As nanostructured materials are dominating the scene in the 21st Century, their potential influence on future products and services is enormous. This has led to a huge advance in research and development efforts related to nanoscale materials and devices. As such, researchers are willing to engineer complex multifunctional and, to a certain degree, smart devices and systems. There is consequently a request for a higher level of complexity in materials design, that is, in other words, combining multiple functionalities in the same nanostructure. ${ }^{1}$

Metal oxides (MOs) are a very important family of nanomaterials, having unique properties and advantageous functionalities that clearly are attractive for a number of applications ranging from electronic devices to energy conversion. ${ }^{2}$ Titanium dioxide (titania, $\mathrm{TiO}_{2}$ ) nanoparticles (NPs), because of their versatility, are a well-investigated class of MOs. Indeed, they are widely used in everyday applications, becoming by far the most popular material in light-to-energy conversion and storage. ${ }^{3}$ The "sun" of $\mathrm{TiO}_{2}$ as photocatalyst rose indeed in Japan more than 4 decades ago, when a paper by Honda and Fujishima about semiconductor photo-electrochemistry was published in $1972 .^{4}$ This initiated research on liquid junction solar cells and semiconductor-assisted photocatalysis. ${ }^{5}$ The photocatalytic (PC) mechanism is now well known: when the surface of a semiconductor material is irradiated with photons having energy higher than or equal to its band gap energy $\left(E_{\mathrm{g}}\right)$, photo-electrons $\mathrm{e}^{-}$and photo-holes $\mathrm{h}^{+}$are generated. ${ }^{6}$ Taking advantage of this phenomenon, multifunctional nanomaterials might be engineered-that is, simultaneous PC and antibacterial activities have been shown to exist in silver-modified titania. ${ }^{7}$

Furthermore, Japan was also the cradle of that phenomenon that was named "multicolour photochromism" by their discoverers, Tatsuma's group and, once again, Fujishima's

Received: July 1, 2018

Accepted: August 10, 2018

Published: August 24, 2018 
group. ${ }^{8}$ This was found exploiting the PC phenomenon in anatase $\mathrm{TiO}_{2}$ films loaded with silver NPs when triggered by UV-light. This outcome led Parkin et al. to demonstrate a relationship between the photochromic state of a $\mathrm{Ag}-\mathrm{TiO}_{2}$ thin-film and its UV-light PC activity, ${ }^{9}$ thus showing multifunctionality within the $\mathrm{Ag}-\mathrm{TiO}_{2}$ system. Following on from these findings, Tobaldi and co-authors, first reported the photochromism and PC activity of multifunctional silvermodified $\mathrm{TiO}_{2}$ NPs, triggered by a purely visible white-light. ${ }^{10}$ It has also been recently shown that a nanomaterial exhibiting reversible color properties can be engineered by coupling copper and $\mathrm{TiO}_{2}$, and the redox process from $\mathrm{Cu}^{2+}$ to $\mathrm{Cu}^{+}$ linked to a change in color, can be simply controlled by regulating the light source (UV or visible light) and exposure time. ${ }^{11}$ Hence, decorating titania with a noble metal can yield to a purely inorganic photochromic noble-metal/MO hybrid nanomaterial. Conversely, most of the existing photochromic systems are based on polymers or organogels containing organic moieties, thus displaying limitations for being implemented on commercial devices. ${ }^{12}$

Besides, $\mathrm{TiO}_{2}$ nanomaterials have also been extensively employed for sensing applications, ${ }^{3}$ because of their unique chemical and physical properties as well as the nontoxic and environmentally friendly nature, excellent biocompatibility, and stability. In particular, it has been widely demonstrated that resistive gas sensors based on $\mathrm{TiO}_{2}$ nanostructures are highly effective in detecting both reducing [i.e., $\mathrm{H}_{2}, \mathrm{CO}$, volatile organic compounds (VOCs) $],{ }^{13}$ and oxidizing (e.g., $\mathrm{NO}_{2}, \mathrm{O}_{3}$ ) gases. ${ }^{14} \mathrm{TiO}_{2}$ nanostructures-because of the extremely high surface to volume ratio and their ability to absorb reactive oxygen species at their surface ${ }^{15}$ - can provide a large number of active sites for the interaction with the gas, thus resulting in high sensitivity. Despite this, some drawback related to high working temperatures and long recovery times are the main disadvantages of that material. ${ }^{3}$ Modifications of $\mathrm{TiO}_{2}$ by doping and/or the formation of metal/ $\mathrm{TiO}$ or $\mathrm{MO} /$ $\mathrm{TiO}_{2}$ heterostructures are amongst the simplest ways to enhance the sensitivity and selectivity yet shortening the response/recovery times. ${ }^{16}$

Our previous works were inspired by light and its ability to trigger redox reactions on the surface of a semiconductor nanomaterial when this is decorated with noble-metals NPs (i.e., silver and copper, as in refs 10 and 11 , respectively). Those redox reactions are indeed associated to a reversible change in color of the (photochromic) material. Color is definitely an essential characteristic of Japanese traditional metal art and craft. ${ }^{17}$

As a result, this research was greatly inspired by the Land of the Rising Sun-photocatalysis, ${ }^{4}$ photochromism, ${ }^{8}$ and Japanese traditional alloys. ${ }^{17}$ Shibuichi-a copper-silver alloy used mainly for sword ornaments, that is, tsuba-is one of the most representative Japanese traditional alloys. Shibuichi means literally "one-fourth", to indicate its standard formulation of a copper alloy containing $25 \%$ of silver. ${ }^{17}$ Hence, we designed a multifunctional photochromic/gas-sensing nanomaterial, made with $\mathrm{TiO}_{2}$ decorated expressly with copper and silver having the $\mathrm{Cu} / \mathrm{Ag}$ molar ratio constrained to be 3:1-that is, one part of $\mathrm{Ag}$, and three parts of $\mathrm{Cu}$. As far as we know, this is the first research of its kind involving multifunctionality (i.e., UV and most remarkably visible-light photochromism as well as gassensing properties) on $\mathrm{TiO}_{2}$ modified with $\mathrm{Ag}$ NPs and $\mathrm{Cu}_{x} \mathrm{O}$ nanoclusters, certainly without neglecting the particular ratio of the noble metals used in here. As a matter of fact, previous research works involved $\mathrm{TiO}_{2}$ modified with $\mathrm{Cu}$ and $\mathrm{Ag}$, but solely with a view limited to PC or antibacterial applications. ${ }^{18,19}$

\section{RESULTS AND DISCUSSION}

2.1. QPA and Microstructural Analyses: XRD and HRSTEM. X-ray diffraction (XRD) patterns of the specimens are shown in Figure 1. Results of the XRD-quantitative phase

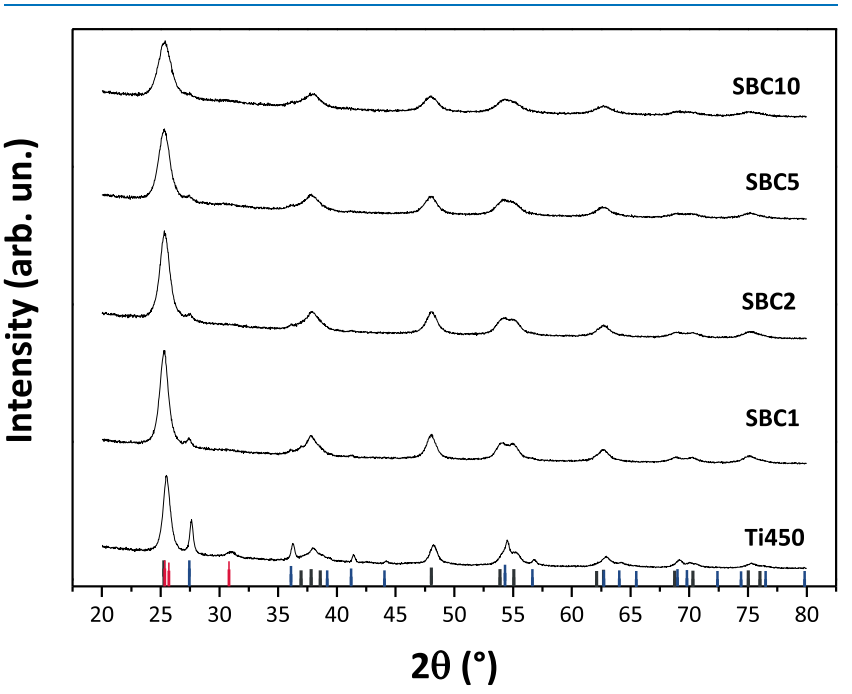

Figure 1. XRD patterns of synthesized specimens. The vertical bars represent the XRD reflections of anatase (black, JCPDS-PDF card no. 21-1272), rutile (blue, JCPDS-PDF card no. 21-1276), and brookite (red, JCPDS-PDF card no. 29-1360-only the three most intense reflections were reported here).

analysis (QPA) analysis are listed in Table 1, and a graphical output of a Rietveld QPA refinement is shown in Figure S1. Unmodified titania is composed of all the three main natural occurring $\mathrm{TiO}_{2}$ polymorphs/anatase (56.5 wt \%), rutile (19.8 wt \%), and brookite (23.6 wt \%). The presence of brookite has to be linked to the strongly acidic synthesis conditions. ${ }^{20}$ The modification with both copper and silver led to a huge decrease in the weight fraction of rutile and brookite, meaning a delay in the anatase-to-rutile phase transition (ART). Specimen SBC1, for instance, is composed of $94.5 \mathrm{wt} \%$ anatase, $4.4 \mathrm{wt} \%$ rutile, and 1.2 wt \% brookite. By contrast, SBC10 contains 93.7 wt \% anatase, 3.7 wt \% rutile, and 2.6 wt \% brookite, see Table 1 . Actually, in Shibuichi specimens, the trend with the increase in the $\mathrm{Ag}+\mathrm{Cu}$ mol \% content is a slight decrease in the anatase and rutile fractions (from 94.5 to $93.7 \mathrm{wt} \%$, and from 4.4 to 3.7 wt \%, respectively) and a small increase in brookite amount-from 1.2 to $2.6 \mathrm{wt} \%$. The delay in the ART, when including $\mathrm{Ag}+\mathrm{Cu}$ in the system, can be explained as being caused by a grain-boundary pinning (Zener drag), ${ }^{21}$ which culminates in delaying the ART - that is a nucleation-growth mechanism. ${ }^{22}$ Microstructural information, as extracted by means of whole powder pattern modeling (WPPM), is listed in Tables 2 and 3; an example of WPPM graphical output is shown in Figure S2. From the negligible differences in unit cell volumes, it can be inferred that neither $\mathrm{Cu}$ nor $\mathrm{Ag}$ entered the $\mathrm{TiO}_{2}$ lattice. Indeed, the ionic radii of ${ }^{[\mathrm{VI}]} \mathrm{Cu}^{1+/ 2+},{ }^{[\mathrm{VI}]} \mathrm{Ag}^{1+/ 2+}$, and ${ }^{[\mathrm{VI}]} \mathrm{Ti}^{4+}$ are $0.77 / 0.73,1.15 / 0.94$, and $0.61 \AA$, respectively. ${ }^{23}$ Modification of $\mathrm{TiO}_{2}$ with $\mathrm{Ag}+\mathrm{Cu}$ also led to a decrease in the mean average diameter of the crystalline domains, cf Table 3 and Figure 2a-c. Anatase domains in 
Table 1. Rietveld Agreement Factors and Crystalline Phase Composition of the Unmodified and $\mathrm{Cu} / \mathrm{Ag}-\mathrm{Modified} \mathrm{TiO}_{2}{ }^{a}$

\begin{tabular}{|c|c|c|c|c|c|c|c|}
\hline \multirow[b]{2}{*}{ sample } & \multirow[b]{2}{*}{ no. of variables } & \multicolumn{3}{|c|}{ agreement factors } & \multicolumn{3}{|c|}{ phase composition (wt \%) } \\
\hline & & $R_{\mathrm{F}}^{2}(\%)$ & $R_{\mathrm{wp}}(\%)$ & $\chi^{2}$ & anatase & rutile & brookite \\
\hline Ti450 & 20 & 3.54 & 4.03 & 1.74 & $56.5 \pm 0.1$ & $19.8 \pm 0.2$ & $23.6 \pm 0.6$ \\
\hline SBC1 & 19 & 2.27 & 3.01 & 1.59 & $94.5 \pm 0.1$ & $4.4 \pm 0.2$ & $1.2 \pm 0.2$ \\
\hline $\mathrm{SBC} 2$ & 18 & 2.04 & 3.48 & 1.56 & $93.4 \pm 0.1$ & $4.8 \pm 0.2$ & $1.8 \pm 0.2$ \\
\hline SBC5 & 16 & 2.72 & 3.42 & 1.66 & $93.6 \pm 0.1$ & $4.2 \pm 0.2$ & $2.2 \pm 0.3$ \\
\hline SBC10 & 17 & 4.22 & 3.16 & 1.64 & $93.7 \pm 0.1$ & $3.7 \pm 0.2$ & $2.6 \pm 0.4$ \\
\hline
\end{tabular}

${ }^{a_{\text {There were }}} 2285$ observations for every refinement; the number of anatase, rutile, and brookite reflections was 32,31 , and 154 , respectively.

unmodified $\mathrm{TiO}_{2}$ have an average diameter of $10.4 \mathrm{~nm}$, rutile of $14.4 \mathrm{~nm}$, and brookite averages of $7.0 \mathrm{~nm}$. Shibuichi modification of $\mathrm{TiO}_{2}$ led not only to smaller crystalline domain diameters, but also to narrower size distribution of those crystalline domains, refer to Table 3 and Figure $2 a-c$. The average crystalline domain diameter in anatase and rutile that are in SBC1 is 6.7 and $11.2 \mathrm{~nm}$, respectively; on the other hand, that of anatase and rutile in SBC10 is $4.6 \mathrm{~nm}$ for both the polymorphs. This outcome means that copper and silver NPs likely nucleate on the grain boundaries, pinning them, thus limiting their further growth. This also explains the observed delay of the ART and crystal growth. The decrease in the size of anatase nanocrystals is also confirmed by Raman analysis: the Raman $E_{\mathrm{g}}$ mode of anatase is shifted toward higher energies in the $\mathrm{Ag}+\mathrm{Cu}$ specimens, thus confirming their reduced dimensions (cf Table S1). ${ }^{24}$

High-resolution scanning transmission electron microscopy (HR-STEM) experiments were performed on the Shibuichi samples with the highest $\mathrm{Ag}+\mathrm{Cu}$ concentrations (SBC5 and SBC10) in order to investigate the possible formation of a metallic@ $\mathrm{TiO}_{2}$ heterostructure and to determine their morphology and microstructure. Figure 3a shows a lowmagnification STEM-high-angle annular dark-field imaging (HAADF) micrograph of the sample SBC5, in which two distinct kinds of NPs, displaying two distinct contrasts, can be clearly seen. A single NP displaying a brighter contrast (highlighted by the green arrow) can be observed in contact with a matrix of agglomerated NPs showing a darker contrast. NPs displaying the brighter contrast are scarce and hard to find. To get more information on the nature of the NPs, they were investigated by a combination of energy dispersive X-ray spectroscopy (EDS) and high-resolution TEM (HR-TEM) techniques, that is, a powerful tool to extract structural and chemical information at the nanoscale. ${ }^{25}$ A darker contrast in STEM-HAADF images highlights materials having lower atomic number and/or lower mass density and/or lower thickness. Thus, these NPs showing a darker contrast correspond to $\mathrm{TiO}_{2}$ NPs. This is confirmed by the EDS spectrum acquired on these NPs (displayed in red in Figure $3 \mathrm{~b})$. The EDS spectrum acquired at the center of the brighter particle (displayed in blue in Figure $3 b$ ) highlights the presence of $\mathrm{Ag}$. It has to be highlighted that $\mathrm{Cu}$ signal can be seen in both the NPs. However, $\mathrm{Cu}$ signal can emerge from the specimen, but it might also come from the TEM sampleholder or even from the TEM column, thus making a univocal conclusion difficult. Figure $3 c$ displays the HR-STEM ADF micrograph of a facetted NP standing in the vacuum and showing a brighter contrast. These NPs have a diameter typically between 7 and $10 \mathrm{~nm}$ and, as it can be clearly seen from Figure 3c, they are crystalline. Automatic indexation of the fast Fourier transform (FFT) pattern (displayed in the inset) performed on one of the facet revealed that the NP corresponds to the $\mathrm{Ag}$ face-centered cubic structure in the [011] zone axis. Same results have been obtained on all the investigated NPs, showing this kind of bright contrast. This is also confirmed by the EDS spectrum acquired at the center of the NP (displayed in Figure 3d), which highlights the presence of the Ag lines. A HR-STEM-HAADF micrograph of the $\mathrm{TiO}_{2} \mathrm{NPs}$ is shown in Figure S3. All of the $\mathrm{TiO}_{2}$ NPs are crystalline with a diameter between 1.8 and $8 \mathrm{~nm}$. A similar analysis is shown in Figure S4 for SBC10 sample. The surface of this sample is flecked due to the presence of smaller but more abundant Ag NPs (diameter between 1.5 and $8 \mathrm{~nm}$ ). These results are in good agreement with the WPPM modeling and clearly show the formation of (at least) an $\mathrm{Ag} @ \mathrm{TiO}_{2}$ heterojunction for the Shibuichi samples.

2.2. Optical Properties: Photochromism. Diffuse reflectance spectroscopy (DRS) spectra of fresh un-irradiated samples are depicted in Figure 4. As per Ti450, a single absorption band is observable at $<360 \mathrm{~nm}$, due to the band-toband transition in titania. ${ }^{26}$ Shibuichi-modified specimens, besides these bands, also display other absorption features. The absorption band located at $>600 \mathrm{~nm}$ is assigned to the $d-d$ electronic transitions in $\mathrm{Cu}^{2+}$. The absorption at around 450 $\mathrm{nm}$ belongs to the electron transferring from the valence band (VB) of $\mathrm{TiO}_{2}$ to $\mathrm{Cu}_{x} \mathrm{O}$ clusters that are around titania (interfacial charge transfer, IFCT) ${ }^{27,28}$ consistent with what was reported in an earlier work, this IFCT band increases itself as the amount of $\mathrm{Cu}$ in the specimens increases. ${ }^{11}$ Furthermore, when the $\mathrm{Cu}$ amount is higher than $1.50 \mathrm{~mol}$ $\%$ (i.e., specimens SBC5 and SBC10), an absorption tail extending itself up to $\sim 575 \mathrm{~nm}$, assigned to interband absorptions in $\mathrm{Cu}_{2} \mathrm{O}$, is also noticeable. ${ }^{29,30}$ Optical signatures of metallic $\mathrm{Ag}^{0}$ (i.e., the surface plasmon resonance band, SPR) are not seen at this un-irradiated stage. This is likely because silver is present as $\mathrm{Ag}_{2} \mathrm{O}$, thus displaying just its IFCT feature mingling itself with that of $\mathrm{Cu}_{x} \mathrm{O}$ clusters around $\mathrm{TiO}_{2}{ }^{31}$

When the $\mathrm{Ag}+\mathrm{Cu}$-modified specimens are exposed to UVA light, progressive changes are observable to their optical spectra, as shown in Figure S5a-d. As per SBC1, as the UV-A irradiation time increases, there is also a gradual decrease in the $\mathrm{Cu}^{2+} \mathrm{d}-\mathrm{d}$ band, thus being accompanied by a continuing increase in the band due to the IFCT. Interestingly, with only $0.25 \mathrm{~s}$ of UV-A irradiation time, also the band belonging to the interband absorptions in $\mathrm{Cu}_{2} \mathrm{O}$ starts to appear (and its magnitude increases with the irradiation time as well). These phenomena imply that upon UV-A irradiation, the $\mathrm{Cu}^{2+}$ is swiftly and gradually reduced to its cuprous oxidation state. ${ }^{11}$ There is also no signature of the appearance of the $\mathrm{Ag}^{0} \mathrm{SPR}$ band, likely because of the much reduced amount of silver. With higher mol \% amounts of $\mathrm{Ag}+\mathrm{Cu}$ (specimens SBC2, SBC5, and SBC10), qualitatively the same change in the optical features as in SBC1 was observed. It is worth to highlight that the SPR band in $\mathrm{Ag}^{0}$ is not detected even with 


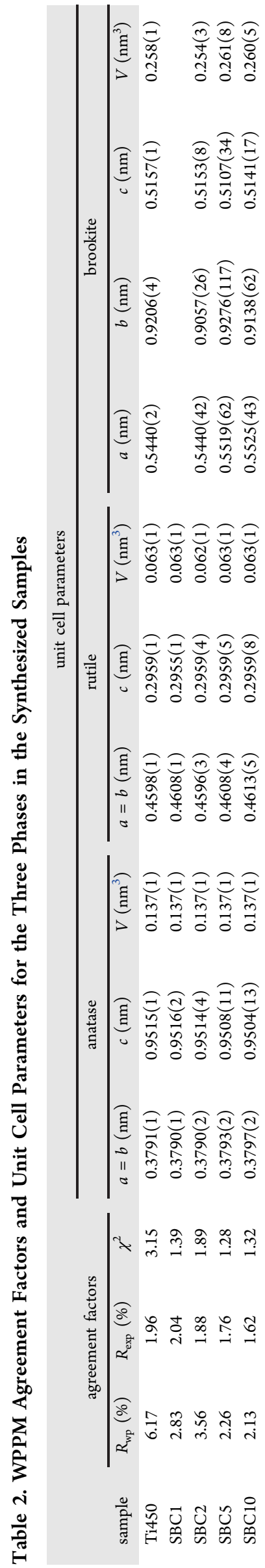

higher amounts of silver, probably because the optical bands of copper cover that of $\mathrm{Ag}^{0}$ SPR. However, an indirect evidence of the reduction of silver into $\mathrm{Ag}^{0}$ after light exposure is given by Raman spectroscopy. As shown in Figure S6, the Raman signal is enhanced in the specimen that has been subjected to UV-A irradiation, thus indeed proving the presence, in this latter, of metallic $\mathrm{Ag}$, giving rise to the surface-enhanced Raman scattering effect. ${ }^{3}$

These changes in the optical properties (i.e., photochromism) are caused, mechanistically, by the PC process in titania: when $\mathrm{TiO}_{2}$ specimens are irradiated with a light having supra $E_{\mathrm{g}}$ energy, the electron that migrated to the conduction band $(\mathrm{CB}$ ) is able to reduce the $\mathrm{CuO}$ oxides (and allegedly also the $\mathrm{Ag}_{2} \mathrm{O}$ ) that are clustered around the semiconductor surface. Looking at the evolution of the increase in the IFCT band area in the Shibuichi samples after UV-A irradiation, Figure $5 \mathrm{a}-\mathrm{d}$, it is seen that these all follow a third-order exponential function, for all the $\mathrm{Ag}+\mathrm{Cu}$ modified specimens. This being partly consistent with our previous investigations: indeed, when dealing only with copper-modified $\mathrm{TiO}_{2}$ and $\mathrm{Ag}-\mathrm{TiO}_{2} \mathrm{NPs}$, the best fit was always obtained adopting a double exponential function. ${ }^{11,31}$ This suggesting that, in the case of $\mathrm{Ag}+\mathrm{Cu}$ modified $\mathrm{TiO}_{2}$, the simultaneous adoption of two noble metals increases the degree of complexity of the photochromic phenomenon-there is indeed an electron "pumping" from $\mathrm{TiO}_{2}$ to $\mathrm{CuO}$ and $\mathrm{Ag}_{2} \mathrm{O}$ NPs decorating it.

When specimens are irradiated with the white lamp, the same changes in the optical properties happen, though in a lesser extent, Figure S7a-d. This is better shown in Figure 6a$\mathrm{d}$, and in Table 4, where is listed the time needed to halve the IFCT integrated area-data obtained using both UV-A and visible light are compared. As listed in Table 4, for instance, the time to reach half of the IFCT integrated area in SBC1 using the UV-A radiation is equal to $0.23 \mathrm{~min}$, while, with the visible light, that time is $4.04 \mathrm{~min}$ ( $\sim 18$ times faster using the UV-A lamp). This latter is indeed a striking result, being the time to halve the IFCT-integrated area in a specimen made only of 1 mol $\% \mathrm{Cu}$ and $\mathrm{TiO}_{2}$ and using the very same visible-light source, equal to $10.8 \mathrm{~min}^{11}$ - that is, almost 3 times faster by adding only $0.25 \mathrm{~mol} \%$ of silver and decreasing from 1 to 0.75 mol \% the $\mathrm{Cu}$ content.

On the other hand, specimen SBC10 and UV-A lamp, the time needed to reach half of the final extent of the IFCT integrated area is $9.34 \mathrm{~min}$, versus $33.29 \mathrm{~min}$ when using the Vis-light (approximately 4 times faster). This means that a lamp irradiating with an energy that is $\geq \mathrm{TiO}_{2} E_{\mathrm{g}}$ triggers in a faster way the photochromic effect, through the PC mechanism. However, this also means that the specimens show themselves to be photochromic, even under visible-light exposure. This is explained invoking a different phenomenon, that is, photosensitization of the $\mathrm{Cu}(\mathrm{II}) / \mathrm{TiO}_{2}$ system. Indeed, as suggested by Irie et al., visible light triggers IFCT from the $\mathrm{VB}$ of titania to the $\mathrm{Cu}(\mathrm{II})$ that are grafted onto the surface of $\mathrm{TiO}_{2} \mathrm{NPs}^{27}$ That is to say that the electrons in the $\mathrm{VB}$ of $\mathrm{TiO}_{2}$ are directly transferred to the $\mathrm{CuO}$ decorating the $\mathrm{TiO}_{2} \mathrm{NPs}$, reducing $\mathrm{Cu}^{2+}$ to $\mathrm{Cu}^{+}$, as spectroscopically shown by the decrease in the $\mathrm{Cu}^{2+} \mathrm{d}-\mathrm{d}$ transitions and the resultant increase in the extent of the IFCT band-and visually by the change in color of the specimens, that is, photochromism. A proposed mechanism of these two distinct phenomena is given in Figure $7 \mathrm{a}-\mathrm{c}$, where the energy band diagrams of $\mathrm{TiO}_{2}$, whose surface is modified with $\mathrm{CuO}$ and $\mathrm{Ag}_{2} \mathrm{O}$, are given-the electrochemical potentials of the band edges of $\mathrm{TiO}_{2}, \mathrm{CuO}$, and 
Table 3. Mean Crystalline Domain Size of Anatase (Ant), Rutile (Rt) and Brookite (Brk)—Defined as the Mean of the Lognormal Size Distributions; Maximum Values and Skewness of the Lognormal Size Distributions

\begin{tabular}{|c|c|c|c|c|c|c|c|c|c|}
\hline \multirow[b]{2}{*}{ sample } & \multicolumn{3}{|c|}{ mean crystalline domain diameter } & \multicolumn{3}{|c|}{ mode of the size distribution } & \multicolumn{3}{|c|}{ skewness of the size distribution } \\
\hline & $\left\langle D_{\text {ant }}\right\rangle(\mathrm{nm})$ & $\left\langle D_{\mathrm{rt}}\right\rangle(\mathrm{nm})$ & $\left\langle D_{\text {brk }}\right\rangle(\mathrm{nm})$ & Ant (nm) & $R_{t}(\mathrm{~nm})$ & Brk (nm) & Ant $(\mathrm{nm})$ & $R_{t}(\mathrm{~nm})$ & Brk (nm) \\
\hline Ti450 & $10.4 \pm 0.7$ & $14.4 \pm 0.6$ & $7.0 \pm 0.1$ & $9.4 \pm 0.6$ & $9.9 \pm 0.4$ & $5.3 \pm 0.1$ & $0.8 \pm 0.1$ & $1.8 \pm 0.1$ & $1.4 \pm 0.1$ \\
\hline SBC1 & $6.7 \pm 0.3$ & $11.2 \pm 0.1$ & & $5.3 \pm 0.2$ & $9.4 \pm 0.1$ & & $1.3 \pm 0.1$ & $1.1 \pm 0.1$ & \\
\hline SBC2 & $5.2 \pm 0.8$ & $9.4 \pm 0.3$ & $5.3 \pm 1.4$ & $4.0 \pm 0.1$ & $8.2 \pm 0.3$ & $4.6 \pm 1.2$ & $1.4 \pm 0.1$ & $0.9 \pm 0.1$ & $1.0 \pm 0.1$ \\
\hline SBC5 & $5.1 \pm 0.1$ & $5.8 \pm 0.8$ & $5.7 \pm 0.9$ & $3.9 \pm 0.1$ & $3.4 \pm 0.5$ & $5.0 \pm 0.8$ & $1.4 \pm 0.1$ & $2.0 \pm 0.1$ & $1.0 \pm 0.1$ \\
\hline SBC10 & $4.6 \pm 0.1$ & $4.6 \pm 0.8$ & $5.8 \pm 1.2$ & $3.5 \pm 0.1$ & $3.2 \pm 0.6$ & $5.5 \pm 0.1$ & $1.4 \pm 0.1$ & $1.8 \pm 0.1$ & $0.6 \pm 0.1$ \\
\hline
\end{tabular}

$\mathrm{Ag}_{2} \mathrm{O}$, with respect to the absolute vacuum scale, were taken from the literature. ${ }^{33}$ [It has to be stressed that, although the data in Figure $7 a-c$ might not reflect a rigorous picture of the absolute values of $\mathrm{CB}$ and $\mathrm{VB}$ potentials of the materials studied here, they provide a reasonable estimate of the relative band edge positions.] In both cases (UV-A and visible-light sources), $\mathrm{TiO}_{2}$ acts itself as an electron shuttle. ${ }^{34}$

Photochromism is, per se, a reversible change in color (and/ or optical absorption spectra) under electromagnetic radiation. $^{35}$ Reversible photoswitches of specimens SBC1 and SBC2 were thus investigated. Specimens were irradiated for 10 or $30 \mathrm{~s}$ with visible light (irradiance $=50 \mathrm{~W} \mathrm{~m}^{-2}$ ), then the reversibility of the process was triggered by annealing the irradiated specimens in a dark oven at $100{ }^{\circ} \mathrm{C}$ for $15 \mathrm{~min}$. As displayed in Figure $8 \mathrm{a}-\mathrm{d}$, SBC1 and SBC2 exhibit similar changes, both specimens show an increase in the $\Delta R_{t}$ value from the un-irradiated state after the first exposure to visible light. This is followed by a partial recovery of the initial virgin state after annealing the samples in the dark at $100{ }^{\circ} \mathrm{C}$ for 15 min. However, after that initial loss in the initial $R \%$ value, very close reflectance values are obtained from the 4th switching cycle on, as a clear and repeatable gap is noticeable for both specimens, exhibiting a high degree of stability and repeatability in the switching values for repeated cycles (up to a total of 14), as reported in Figure 8a,b. This initial instability seems to be originated from the swift decrease from the virgin state: the time granted for the annealing did not seem enough to fully reverse it.

2.3. Electrical and Gas-Sensing Properties. The electrical behavior of the prepared sensors was first investigated by recording the resistance of the sensitive films directly printed on the alumina substrates, in the temperature range of $100-400{ }^{\circ} \mathrm{C}$ in the presence of dry air. In order to favor the complete desorption of humidity and other species likely adsorbed during environmental exposure, each sensor was first allowed to stabilize at $400{ }^{\circ} \mathrm{C}$, and then, the resistance was recorded during a $50{ }^{\circ} \mathrm{C}$ step decrease of the temperature. The plots of the resistance versus temperature of pure $\mathrm{TiO}_{2}$ and $\mathrm{Ag}$ $+\mathrm{Cu}$ (Shibuichi)-modified samples are reported in Figure 9. All samples show a decrease in the resistance with increase in the temperature, according to typical semiconductor behavior in the whole range of temperatures. Ti450 shows two linear regions with different slopes, in the range 150-250 and 250$400{ }^{\circ} \mathrm{C}$, respectively. This can be attributed to a strong adsorption of oxygen species which, in turn, act increasing the electrical resistance. As known, MOs are able to adsorb oxygen species as ions $\left({ }^{\bullet} \mathrm{O}_{2}^{-}, \mathrm{O}^{-}, \mathrm{O}^{2-}\right)$ on their surface as a function of the temperature. ${ }^{36}$ This implies that electrons are subtracted from the bulk, increasing the electrical resistance. Furthermore, a different equilibrium between adsorption and desorption of these species was established as a function of the temperature. Therefore, if adsorption prevails over desorption, a large quantity of oxygen is adsorbed on the MO surface, which leads to a stronger removal of electrons from the bulk. For an $n$-type semiconductor as $\mathrm{TiO}_{2}$, this results in an increase of the resistance. ${ }^{37}$ According to this, it is plausible that Ti450 is able to strongly adsorb oxygen in the temperature range of 150$250{ }^{\circ} \mathrm{C}$ showing two different slopes of the log resistance versus temperature in the investigated range.

On the contrary, as per Shibuichi samples (SBC1, SBC2, SBC5, and SBC10), the trend of resistance fluctuation with the temperature is linear in the entire investigated range of temperatures, suggesting a lower ability in adsorbing oxygen species. In addition, the effect of $\mathrm{Ag}+\mathrm{Cu}$ modification is to decrease the electrical resistance in comparison to Ti450 when the load is higher than $2 \mathrm{~mol} \%$ as for SBC2, SBC5, and SBC10 samples. In this regard, it was possible to record the resistance of these samples up to $100{ }^{\circ} \mathrm{C}$, while for Ti450 and SBC1 the resistance was much higher than the detection limit of the apparatus employed.

The effect of $\mathrm{Ag}+\mathrm{Cu}$ modification of $\mathrm{TiO}_{2}$ on the sensing performance toward acetone was first investigated at different working temperatures. Figure 10 shows the responses of the prepared sensors toward $20 \mathrm{ppm}$ of acetone as a function of the temperature, in the range $100-400{ }^{\circ} \mathrm{C}$. Owing to the high resistance of both Ti450 and SBC1, it was not possible to record the response at a temperature lower than $150{ }^{\circ} \mathrm{C}$. As observed, all sensors show a Gaussian-like behavior, where a first rise of the responses up to $150-200{ }^{\circ} \mathrm{C}$ is followed by a decrease with further increase of the temperature. These typical response behaviors can be simply explained, bearing in mind the effect of different activation energies for the gas adsorption/desorption and reaction processes occurring at the surface. At a low operating temperature, the activation energy is not enough to promote the reaction of acetone molecules with the active species present on the material surface. This leads to a very weak or no alteration of the electrical properties of the sensitive material and, consequently, to a weak response. $^{38}$ On the other hand, the adsorption ability of acetone molecules onto the surface is reduced at higher operating temperatures, thus leading again to a lower response. $^{39}$

Among Shibuichi-based sensors, SBC2 is the one that shows the best performances and have the maximum response $S=9$ at the lowest operating temperature, $150{ }^{\circ} \mathrm{C}$. A further increase of $\mathrm{Ag}+\mathrm{Cu}$ modification of $\mathrm{TiO}_{2}$ over $5 \mathrm{~mol} \%$ as for the SBC10 sample resulted in a strong decrease of the response to acetone. However, all Shibuichi-based sensors showed lower response in comparison to $\mathbf{T i 4 5 0}$, in the whole range of investigated temperatures.

However, response is not the sole parameter that is investigated to define the performances of a gas sensor. In this regard, Figure 11 shows a comparison of the transient responses recorded for each sensor at the operating temper- 

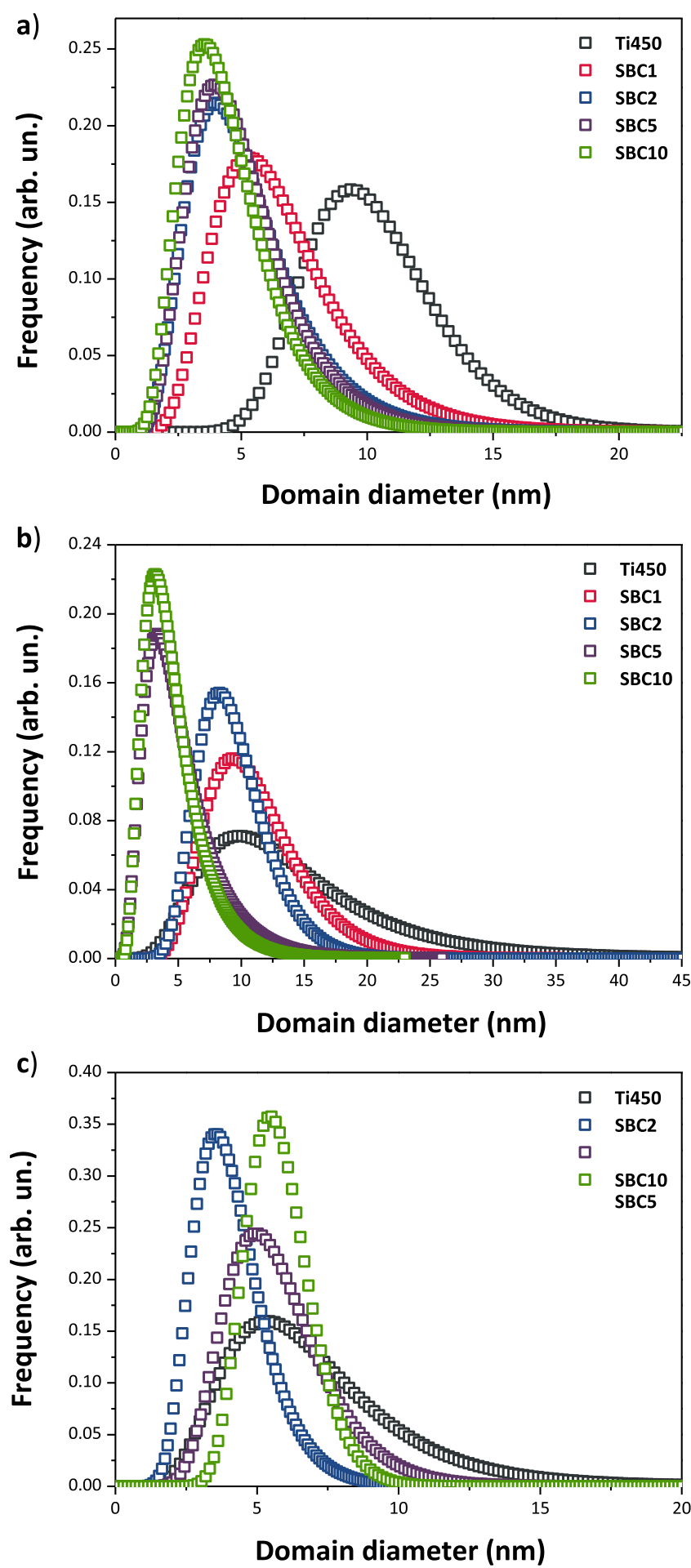

Figure 2. Size distribution, as obtained from the WPPM modeling of (a) anatase, (b) rutile, and (c) brookite, contained in the synthesized specimens.

ature of $200{ }^{\circ} \mathrm{C}$ to a pulse of $20 \mathrm{ppm}$ acetone. Still in a relatively low temperature, all Shibuichi-based sensors show fast signal variations after acetone exposure, reaching the equilibrium state in less than $30 \mathrm{~s}$, which is faster than that observed for Ti450-based sensor (Figure S8a). When the sensors are again exposed to pure air, a fast recovery of the $90 \%$ of response is obtained in less than $30-40 \mathrm{~s}$ on the Shibuichi-based sensors. As per the Ti450-based sensor, it is worth noting that the time at $90 \%$ of response recovery is close to that of the SBC2-based sensor (Fig S8b); nevertheless, the time to the full recovery of the baseline signal is much higher, thus leading to a serious drawback in real applications. Therefore, a positive effect of the incorporation of $\mathrm{Ag}+\mathrm{Cu}$ into $\mathrm{TiO}_{2}$ is to ease the desorption of subproducts of acetone reaction from the surface of the material. In this regard, Dutta et al., ${ }^{40}$ investigating the $\mathrm{CO}$-sensing performance of anatase $\mathrm{TiO}_{2}$, suggested that $\mathrm{CuO}$ incorporation, favoring the decomposition of carbonate intermediate species, aids the desorption of subproduced $\mathrm{CO}_{2}$ and then the recovery time of the sensor. It is well known that the typical sensing mechanism of reducing gases with MOs involves the interaction of gas molecules with chemisorbed oxygen species at the surface. ${ }^{41}$ At temperatures lower than $200{ }^{\circ} \mathrm{C}$, the predominant chemisorbed oxygen species on $\mathrm{MOs}$ are $\mathrm{O}_{2}^{-}$and $\mathrm{O}^{-}$. Therefore, because of the lower activation energy of these species than the more reactive $\mathrm{O}^{2-}$ species, a proposed sensing mechanism of acetone might involve the quasi-chemical reactions, as given by eqs 1 and $2^{42}$

$$
\begin{aligned}
& \left(\mathrm{CH}_{3}\right)_{2} \mathrm{CO}_{\mathrm{ads}}+4 \mathrm{O}_{2, \mathrm{ads}}{ }^{-} \\
& \rightsquigarrow\left(\mathrm{CH}_{3}\right)_{2} \mathrm{CO}_{9}{ }^{4-} \\
& \rightarrow 3 \mathrm{CO}_{2}+3 \mathrm{H}_{2} \mathrm{O}+4 \mathrm{e}^{-} \\
& \left(\mathrm{CH}_{3}\right)_{2} \mathrm{CO}_{\mathrm{ads}}+8 \mathrm{O}_{\mathrm{ads}}{ }^{-} \\
& \rightsquigarrow\left(\mathrm{CH}_{3}\right)_{2} \mathrm{CO}_{9}{ }^{8-} \\
& \rightarrow 3 \mathrm{CO}_{2}+3 \mathrm{H}_{2} \mathrm{O}+8 \mathrm{e}^{-}
\end{aligned}
$$

Accordingly, because the reaction of acetone with surfaceadsorbed oxygen species may involve the formation of carbonates before the evolution to $\mathrm{CO}_{2}$ and $\mathrm{H}_{2} \mathrm{O}$, a similar catalytic effect coming from $\mathrm{CuO}$ and/or $\mathrm{AgO}$ nanoclusters could be the reason of faster recovery times of Shibuichi- $\mathrm{TiO}_{2}$ based sensors in comparison to Ti450.

All investigated sensors show a reduction in the electrical resistance when exposed to acetone, according to n-type semiconductor MOs when they interact with reducing gases. This suggests that the addition of such load of p-type species, like copper, is not enough to alter the typical n-type behavior of anatase $\mathrm{TiO}_{2}{ }^{43}$ Teleki et al., ${ }^{44}$ showed a p-type behavior in a heat-treated 100 wt $\%$ rutile $\mathrm{TiO}_{2}$ sensors toward $\mathrm{CO}$ at 500 ${ }^{\circ} \mathrm{C}$, while the same authors observed a n-type response for a 5 at. $\% \mathrm{Cu} / \mathrm{TiO}_{2}$-based sensor, having a rutile content of $50 \mathrm{wt}$ $\% .{ }^{45}$ On the other hand, Savage et al. ${ }^{46}$ investigated the sensing behavior of mixed anatase-rutile $\mathrm{TiO}_{2}$ toward $\mathrm{CH}_{4}$ and $\mathrm{CO}$ gases. They reported stable $\mathrm{n}$-type response for rutile phase less than 75 wt $\%$ and p-type response for pure rutile. As all Shibuichi samples show contents of anatase higher than $90 \mathrm{wt}$ $\%$ and about 56 wt \% for Ti450 (cf Table 1), this might explain the stable n-type behavior of all the sensors reported here.

Among $\mathrm{Ag}-\mathrm{Cu}$ samples, because of the higher response, lower operating temperature, and reduced electrical resistance, the sensor based on SBC2 was chosen to be investigated for further sensing performances. Figure 12a shows the transient response recorded during subsequent exposure of the SBC2based sensor to different concentrations of acetone ranging from 1 to $40 \mathrm{ppm}$ in dry air at the working temperature of 150 ${ }^{\circ} \mathrm{C}$. The sensor shows a fast reduction of the electrical resistance after acetone exposure. In addition, this sensor is able to quickly and fully recover the baseline resistance after 

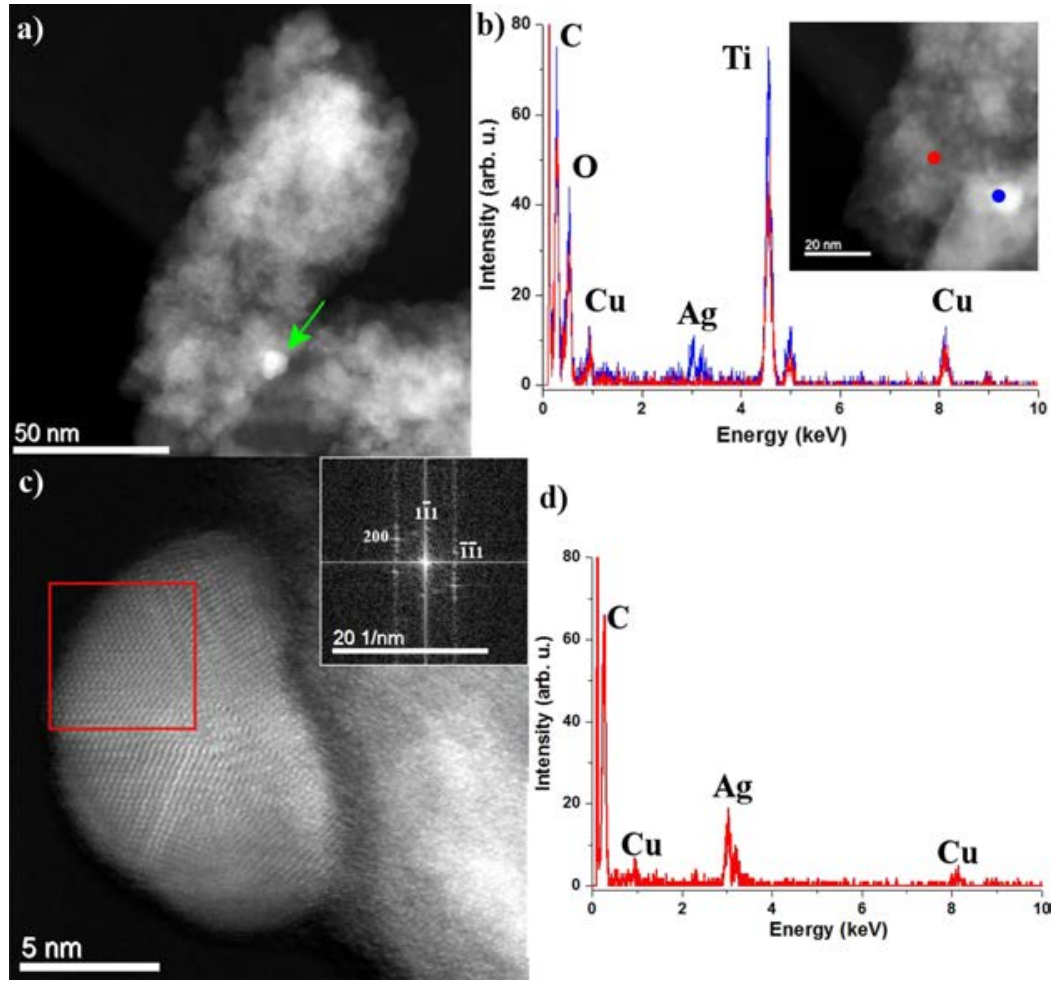

Figure 3. (a) Low-magnification STEM-HAADF micrograph of sample SBC5. The green arrow highlights the presence of a NP having brighter contrast in contact with a matrix of NPs with a darker contrast. (b) EDS spectra acquired on the NPs with the darker and brighter contrasts highlighted by a red and blue circle in the STEM-ADF micrograph displayed in the inset, respectively. (c) HR-STEM ADF micrograph of a NP with a brighter contrast standing in the vacuum. The inset displays the FFT pattern obtained on the area highlighted by the red square. (d) EDS spectrum acquired at the center of the NP displayed in (c).

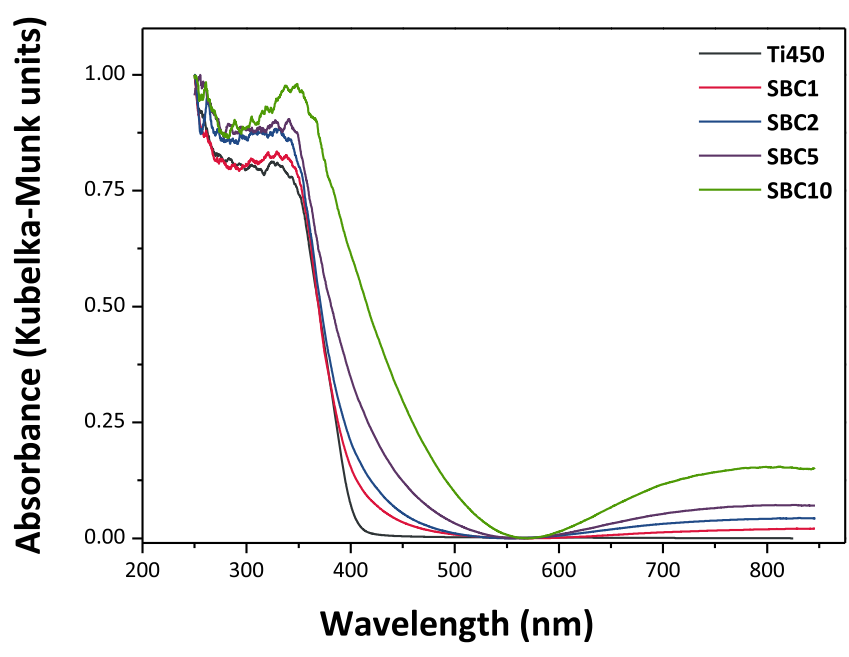

Figure 4. Absorption data, derived by Kubelka-Munk analysis, of the optical spectra (un-irradiated specimens).

each pulse, displaying a perfect reversible behavior. Figure $12 \mathrm{~b}$ shows the calibration curve extrapolated by the above transient responses. In the range of investigated concentration, the response follows a typical $\log -\log$ behavior, which can be fitted by eq 3

$$
\log S=0.37 \cdot \log c+0.47
$$

In eq $3, S$ is the response and $c$ is the concentration of acetone. The determination coefficient $\left(R^{2}=0.994\right)$ suggests a good linear trend between the logarithm of response and the logarithm of concentration, in the studied range. Using this data, a limit of detection lower than $100 \mathrm{ppb}$ of acetone can be estimated, that is 5 times lower compared to the actual stateof-the-art $\mathrm{TiO}_{2}$-based sensors reported in the literature (i.e., $500 \mathrm{ppb})^{47}$

Aiming at exploring the reliability and stability of the sensor, the reproducibility of response was investigated by recording consecutive pulses of acetone in the same and different days, respectively. Figure S9a displays the perfect repeatability and reversibility of response when the sensor was exposed to five consecutive pulses of $5 \mathrm{ppm}$ of acetone in air. In addition, as observed in Figure S9b, the response to $20 \mathrm{ppm}$ acetone, recorded during 3 different days after various cycles of heating-cooling and exposure to different gases, is almost similar, also suggesting excellent long-time reproducibility and stability of the sensing material.

The selectivity of the sensor was also investigated at the optimal operating temperature for acetone, by analyzing the response toward common organic and inorganic gases. The sensor shows low response to typical concentration of the investigated gases (Figure 13a). Only the response to ethanol at the same concentration of the acetone was very similar, suggesting this sensor as a possible candidate for VOCs detection. Finally, in practical applications, acetone coexists with humidity, whose typical aftermath is to decrease the sensitivity of the sensor toward VOCs. The effect of humid air was thus evaluated: ${ }^{48}$ Figure $13 \mathrm{~b}$ shows a comparison of calibration curves recorded in dry and humid air $(50 \% \mathrm{RH}$ at $25{ }^{\circ} \mathrm{C}$ ) operating at the temperature of $150{ }^{\circ} \mathrm{C}$. The presence of humidity causes a decrease in response to acetone from 2- to 5 -folds compared to that obtained in dry condition. Regardless 

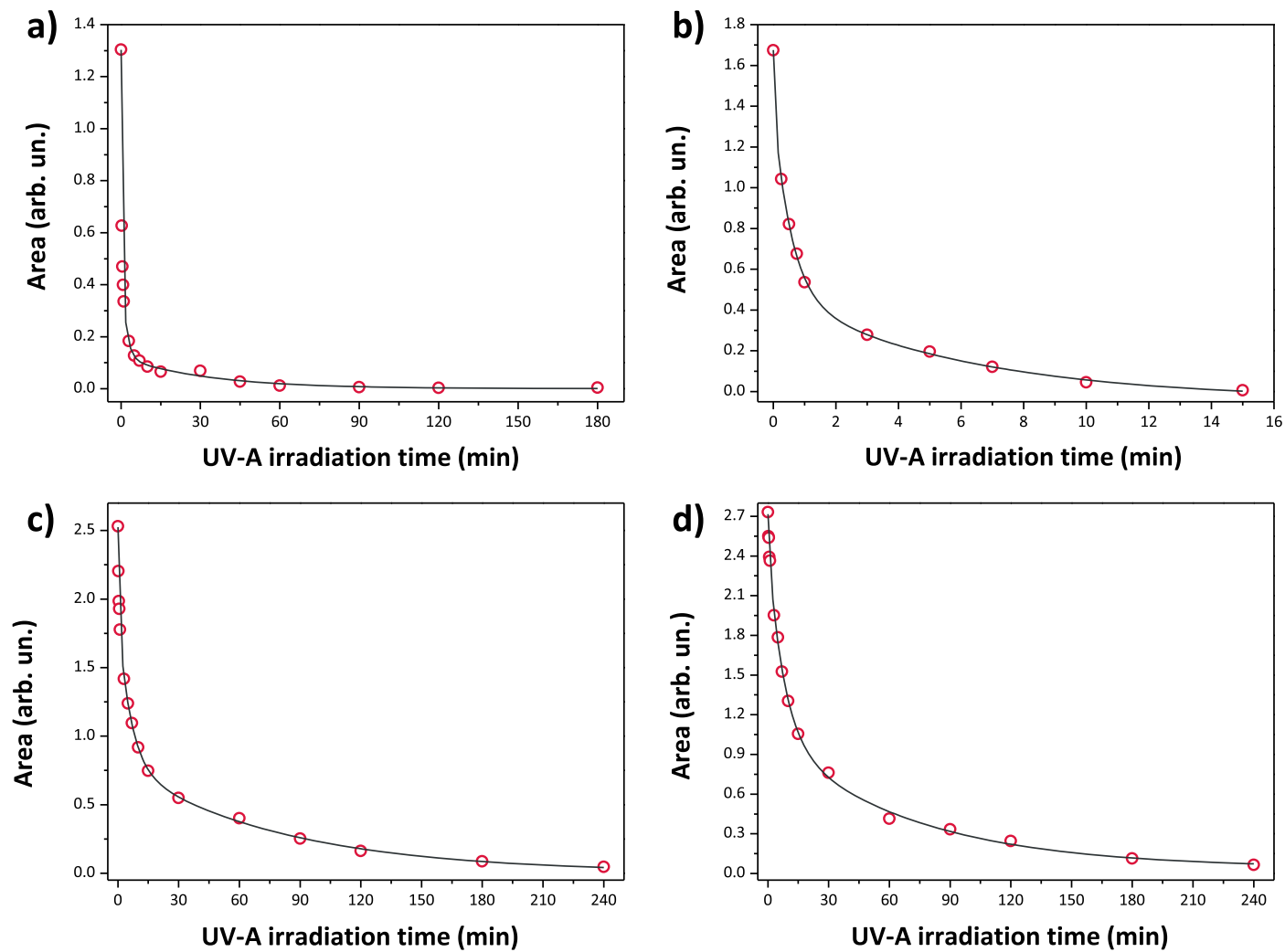

Figure 5. Evolution of the increase in the IFCT band area in the Shibuichi samples after UV-A irradiation. (a) SBC1; (b) SBC2; (c) SBC5; and (d) SBC10. The coefficients of determination $R^{2}$ of the third-order exponential function adopted for the fittings were $\geq 0.9984$.
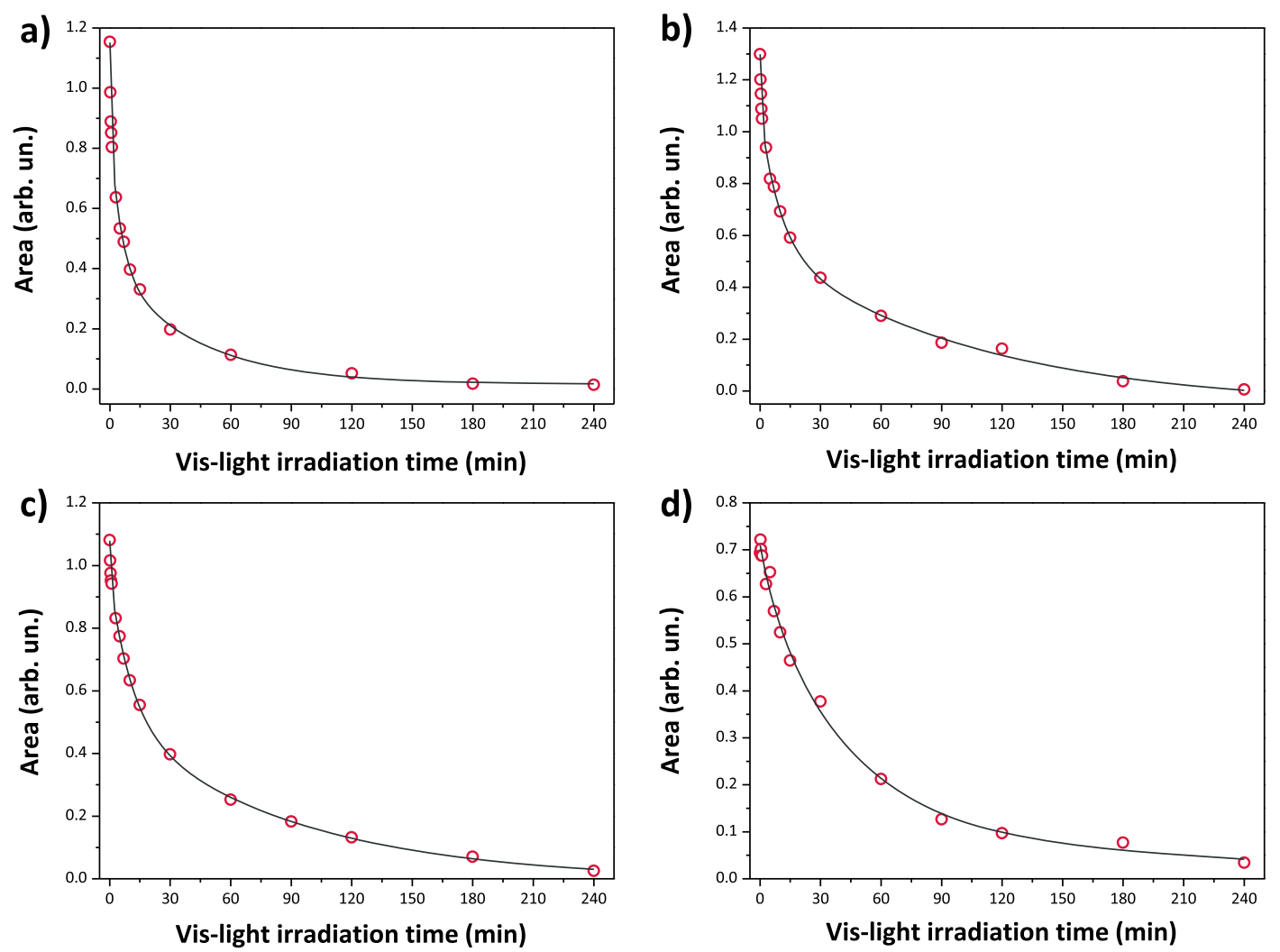

Figure 6. Evolution of the increase in the IFCT band area in the Shibuichi samples after visible-light exposure. (a) SBC1; (b) SBC2; (c) SBC5; and (d) SBC10. The coefficients of determination $R^{2}$ of the third-order exponential function adopted for the fittings were $\geq 0.9923$. 
Table 4. Time to Reach One-Half of the Final Extent of the Integrated IFCT Area, After UV-A and Vis-Light Irradiation

\begin{tabular}{lcc} 
& \multicolumn{2}{c}{$t_{1 / 2}$ IFCT band $(\mathrm{min})$} \\
\cline { 2 - 3 } sample & UV-A & Vis-light \\
SBC1 & 0.23 & 4.04 \\
SBC2 & 0.44 & 11.96 \\
SBC5 & 4.65 & 15.89 \\
SBC10 & 9.34 & 33.29 \\
\hline
\end{tabular}

of that, the sensor was still able to show appreciable response to a concentration of acetone as low as $500 \mathrm{ppb}$.

\section{CONCLUSIONS}

Inspired by the Land of the Rising Sun, $\mathrm{TiO}_{2} \mathrm{NPs}$ have been decorated with one part of silver to three parts of copperShibuichi. This made a multifunctional nanomaterial, which shows simultaneously photochromism and gas-sensing abilities. It has been shown that photochromism might be triggered by UV-A and, most strikingly, also visible light. However, two distinct phenomena are responsible of the same effect. When using a UV-A lamp (i.e., an energy $\geq E_{\mathrm{g}}$ ), photocatalysis sensu strictu happened to activate photochromism. On the other hand, when employing a visible light, a photosensitization of $\mathrm{Cu}(\mathrm{II}) / \mathrm{TiO}_{2}$ system happens, triggering photochromism. Gassensing tests showed that the modification of $\mathrm{TiO}_{2} \mathrm{NPs}$ with $\mathrm{Ag}+\mathrm{Cu}$ leads to an improvement of the transient response to acetone, shortening the response an recovery times in comparison to the pure $\mathrm{TiO}_{2}$-based sensor even working at a relatively low temperature of $150{ }^{\circ} \mathrm{C}$. Furthermore, it also exhibited a lower detection limit for acetone ( 5 times lower) compared to state-of-the-art $\mathrm{TiO}_{2}$-based sensors reported in the literature, for example, $100 \mathrm{ppb}$ in this work versus $500 \mathrm{ppb}$ in previous work. Still, among the Shibuichi samples, a gas sensor based on $\mathrm{TiO}_{2}$ decorated with $2 \mathrm{~mol} \% \mathrm{Ag}+\mathrm{Cu}$ showed excellent sensing performance toward VOCs, exhibiting good sensitivity, stability, and selectivity in comparison with other inorganic gases, as well as capability of being implemented at lower operating temperature. All these characteristics together make our material attractive for real commercial application.

\section{EXPERIMENTAL SECTION}

4.1. Sample Preparation. An adapted aqueous sol-gel method, developed by the authors, was used for the synthesis of $\mathrm{TiO}_{2}$-based nanomaterials; precise detail of it can be found elsewhere. ${ }^{49}$ To do the $\mathrm{Ag} / \mathrm{Cu}$-modified $\mathrm{TiO}_{2}$, stoichiometric amounts of silver nitrate ( $1 \mathrm{M}$ aqueous solution, SigmaAldrich) and copper(II) nitrate trihydrate (Aldrich, $\geq 98.5 \%$ ) were added to the sol, which had a concentration of $1 \mathrm{M} \mathrm{Ti}^{4+}$. The $\mathrm{Ag} / \mathrm{Cu}$ molar ratio was strictly constrained to be $1: 3$, to follow the Shibuichi formulation. Four $\mathrm{Ag} / \mathrm{Cu}$-modified sols were prepared, with $(\mathrm{Ag}+\mathrm{Cu})$ molar amounts equal to $1,2,5$ and $10 \mathrm{~mol} \%$ [i.e., in the case of $(\mathrm{Ag}+\mathrm{Cu})=1 \mathrm{~mol} \%, \mathrm{Ag}$ molar amount was $0.25 \mathrm{~mol} \%$, and $\mathrm{Cu}$ was $0.75 \mathrm{~mol} \%$, with $\mathrm{Ag} / \mathrm{Cu}=0.25: 0.75=1: 3]$. Afterward, dried gels were thermally treated at $450{ }^{\circ} \mathrm{C}$ under a static air flow, using an electric muffle furnace. The heating/cooling rate was $5{ }^{\circ} \mathrm{C} \mathrm{min}^{-1}$, with a $2 \mathrm{~h}$ dwell time at the selected temperature. Samples were referred to as Ti450 (unmodified $\left.\mathrm{TiO}_{2}\right)$, SBC1 $(\mathrm{Ag}+\mathrm{Cu}=1$ $\mathrm{mol} \%), \operatorname{SBC2}(\mathrm{Ag}+\mathrm{Cu}=2 \mathrm{~mol} \%), \operatorname{SBC5}(\mathrm{Ag}+\mathrm{Cu}=5 \mathrm{~mol}$ $\%)$, and $\operatorname{SBC} 10(\mathrm{Ag}+\mathrm{Cu}=10 \mathrm{~mol} \%)$.

\section{Potential Vs AVS}

UV-A light

a)

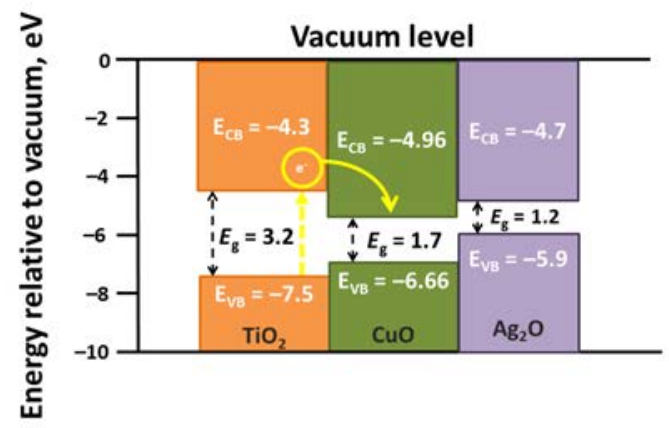

\section{Potential Vs AVS}

Vis-light

b)

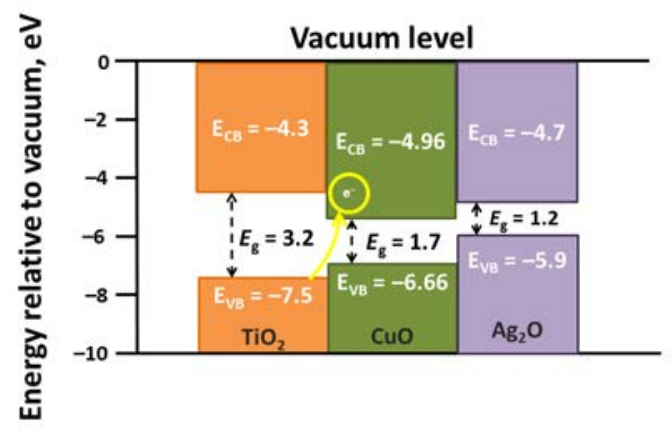

Potential Vs AVS

c)

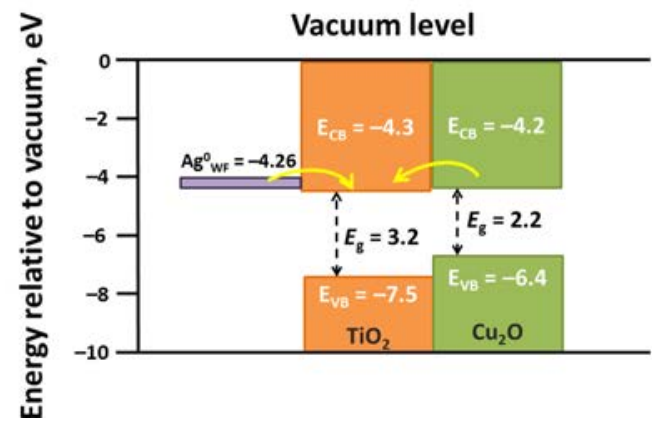

Figure 7. Proposed mechanism for the UV-A and visible-light photochromism. (a) After UV-A exposure, an electron is promoted from the $\mathrm{VB}$ to the $\mathrm{CB}$ of $\mathrm{TiO}_{2}$, a $\mathrm{CB}$ transferring from $\mathrm{TiO}_{2}$ to $\mathrm{CuO}$ is then favored, thus reducing $\mathrm{Cu}^{2+}$ to $\mathrm{Cu}^{+}$. (b) Visible light triggers IFCT from the $\mathrm{VB}$ of titania directly to the $\mathrm{CB}$ of $\mathrm{Cu}^{2+}$ that are grafted on the $\mathrm{TiO}_{2}$ surface, reducing it and promoting the photochromic effect. The same proviso, considering their band edge positions, can be made with $\mathrm{TiO}_{2}$ and $\mathrm{Ag}_{2} \mathrm{O}$. (c) After UV-A and visible-light irradiation, (most of) the $\mathrm{Ag}(\mathrm{I})$ and $\mathrm{Cu}(\mathrm{II})$ oxides have been reduced into $\mathrm{Ag}^{0}$ and $\mathrm{Cu}_{2} \mathrm{O}$. This situation promotes charge separation, as shown by the yellow arrow in the energy band diagram: electrons move themselves from $\mathrm{Ag}^{0}$ to the $\mathrm{CB}$ of $\mathrm{TiO}_{2}$ and from the $\mathrm{CB}$ of $\mathrm{Cu}_{2} \mathrm{O}$ to that of $\mathrm{TiO}_{2}$.

4.2. Sample Characterization. Information about the microstructure of the specimens was attained via advanced $\mathrm{X}$ ray methods. The Rietveld method was used to obtain semiquantitative information about the phase composition of the samples (i.e., not accounting for the presence of amorphous fraction). XRD patterns for QPAs were recorded on a $\theta / \theta$ diffractometer (PANalytical X'Pert Pro, NL), equipped with a fast RTMS detector (PIXcel 1D, PANalytical), 

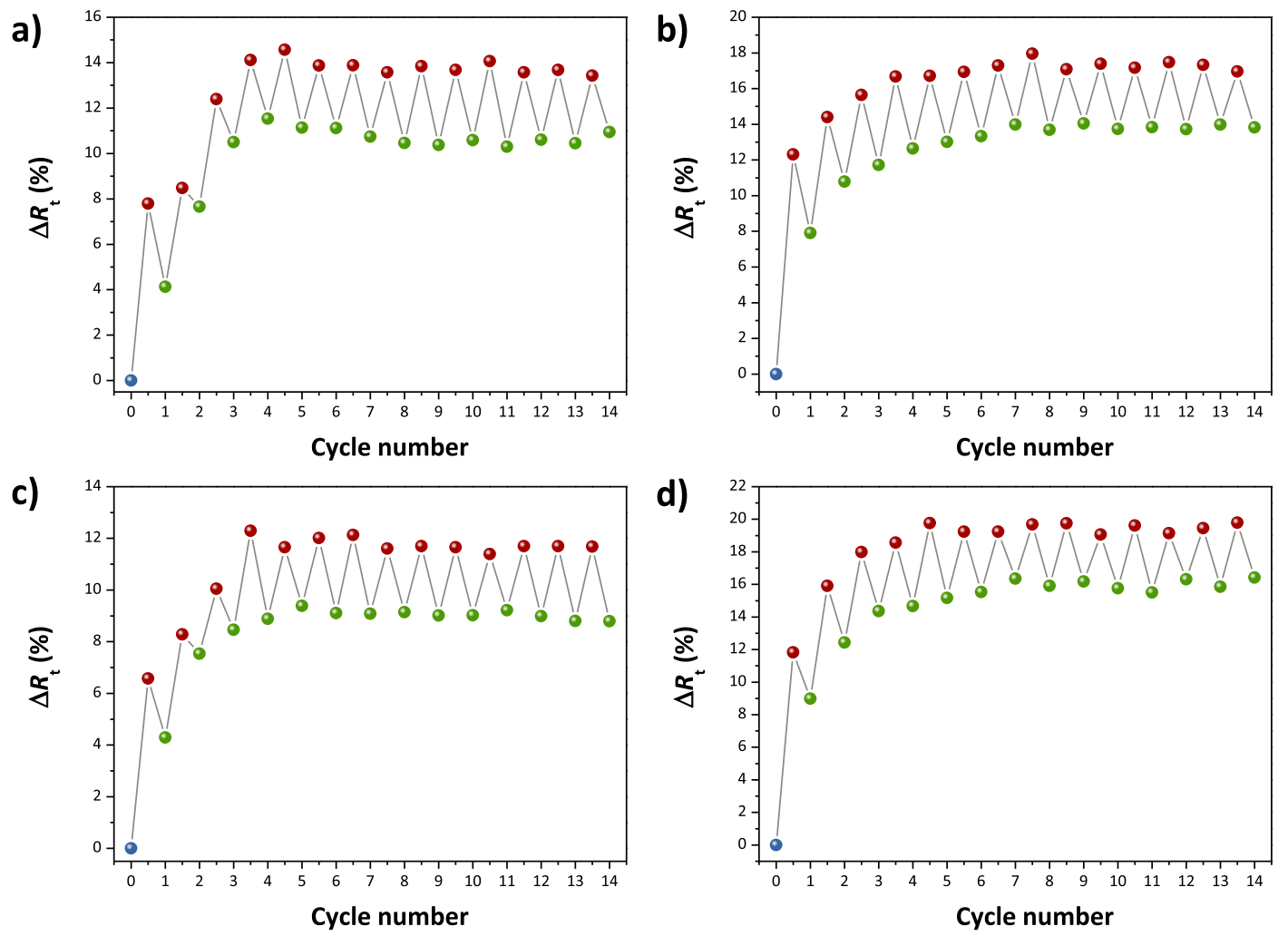

Figure 8. Photochromic recovery switches with repeated visible light (red spheres)/dark@100 ${ }^{\circ} \mathrm{C}$ for 15 min (green spheres) cycles; the blue sphere represent the un-exposed specimen. (a) SBC1 upon $10 \mathrm{~s}$ Vis and $15 \min @ 100{ }^{\circ} \mathrm{C}$; (b) SBC1 upon $30 \mathrm{~s} \mathrm{Vis} \mathrm{and} 15 \mathrm{~min} @ 100{ }^{\circ} \mathrm{C}$; (c) SBC2 upon $10 \mathrm{~s}$ Vis and $15 \mathrm{~min} @ 100{ }^{\circ} \mathrm{C}$; and (d) SBC2 upon $30 \mathrm{~s}$ Vis and $15 \mathrm{~min} @ 100{ }^{\circ} \mathrm{C}$.

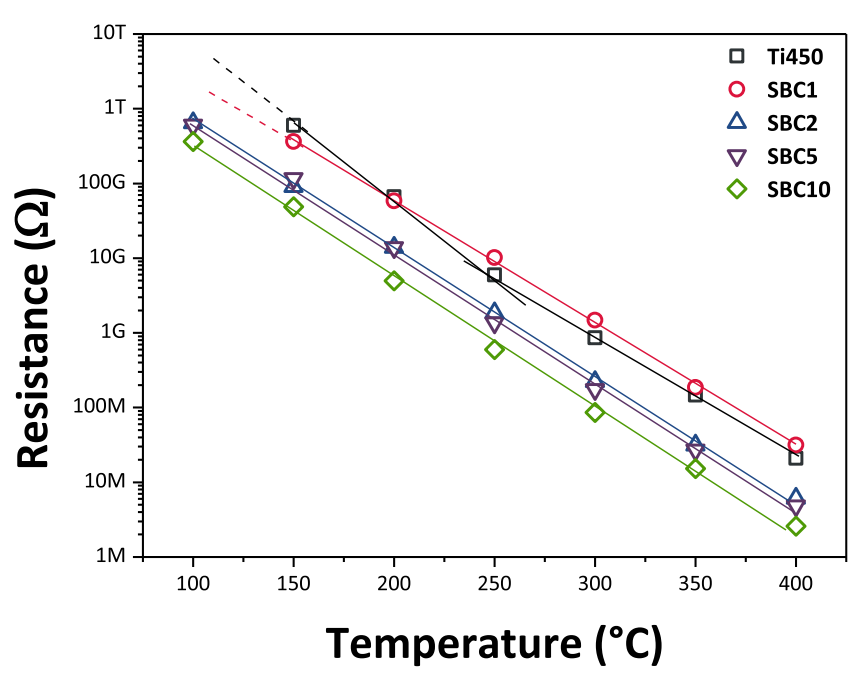

Figure 9. Electrical resistance as a function of the temperature of the as-fabricated gas sensors recorded in dry air.

with $\mathrm{Cu} \mathrm{K} \alpha$ radiation $\left(45 \mathrm{kV}\right.$ and $40 \mathrm{~mA}, 20-80^{\circ} 2 \theta$ range, with a virtual step scan of $0.02^{\circ} 2 \theta$ and a virtual time per step of $200 \mathrm{~s}$ ). Rietveld refinements were accomplished by means of GSAS-EXPGUI software suite, ${ }^{50,51}$ following the refining strategy that we reported previously; ${ }^{31}$ structure models of anatase, rutile, and brookite were taken from the literature. $^{52-54}$ WPPM formalism, ${ }^{55}$ through the PM2K software package, ${ }^{56}$ was used to extract microstructural information from the XRD data. In this latter case, aiming to manipulate data with a high signal-to-noise ratio, XRD patterns were recorded in the same instrument and setup as described above,

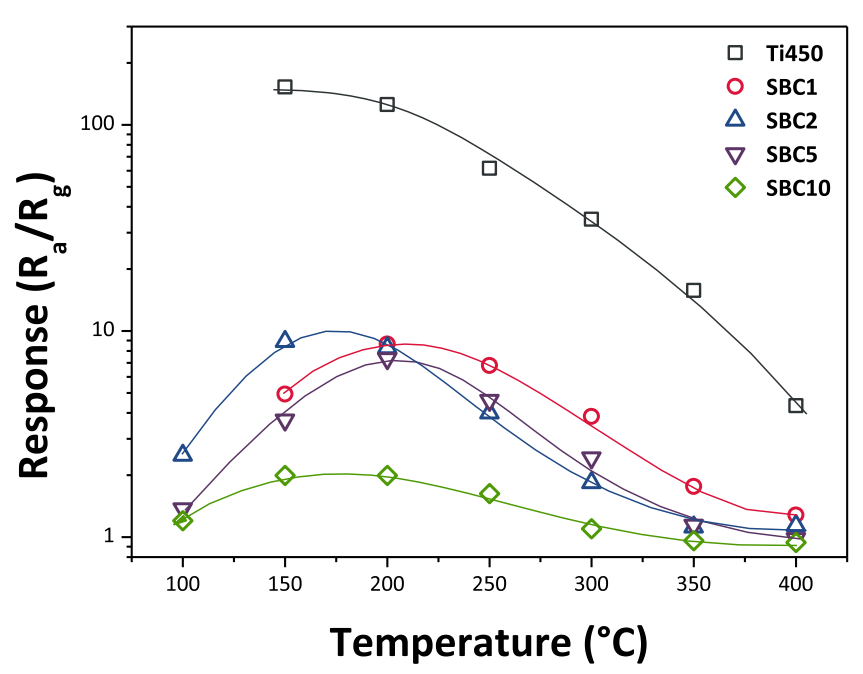

Figure 10. Gas responses toward $20 \mathrm{ppm}$ acetone in dry air of Ti450and Shibuichi-based sensors at different operating temperatures.

but in the $20-145^{\circ} 2 \theta$ range, with a virtual step of $0.1^{\circ} 2 \theta$, and virtual time per step of $500 \mathrm{~s}$. The instrumental contribution was obtained by parameterizing the profile of $14 \mathrm{hkl}$ reflections from the NIST SRM 660b standard $\left(\mathrm{LaB}_{6}\right)$, according to the Caglioti et al. relationship. ${ }^{57}$ The following parameters were refined: background (modeled with a sixth-order Chebyshev polynomial), peak intensities, specimen displacement, lattice parameters, and mean and variance of the size distributions. Crystalline domains were approximated to be spherical with their diameter distributed according to a lognormal curve. 


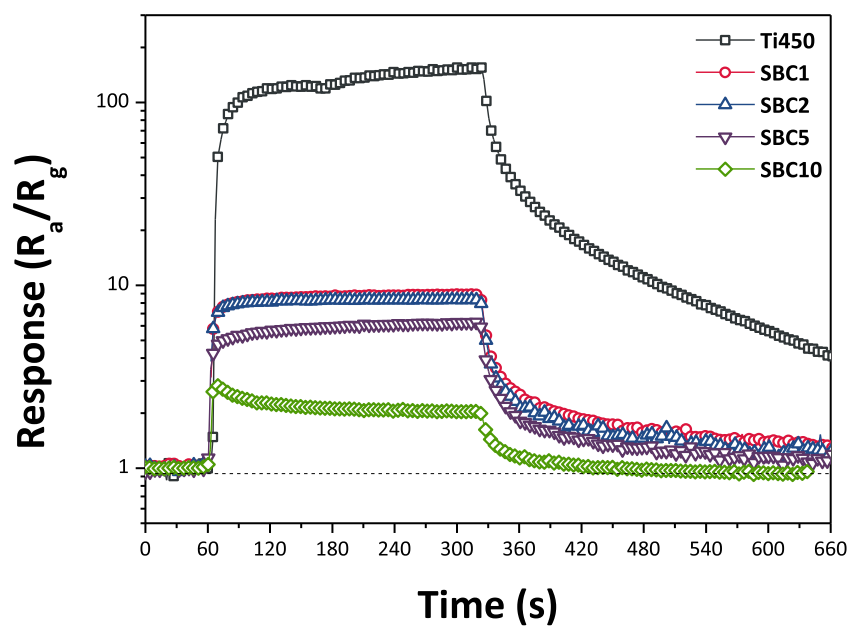

Figure 11. Transient responses toward $20 \mathrm{ppm}$ acetone in dry air of Ti450- and Shibuichi-based sensors at the operating temperature of $200{ }^{\circ} \mathrm{C}$.
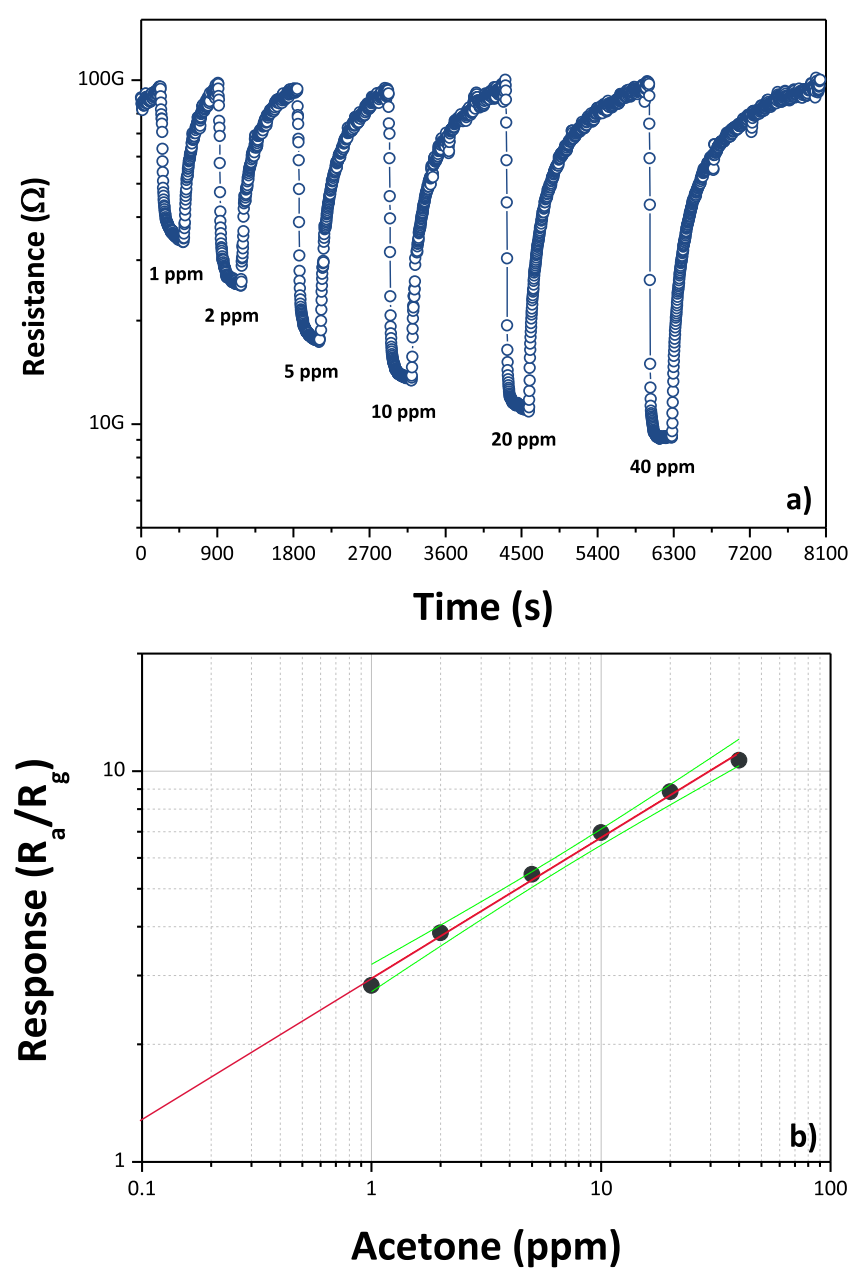

Figure 12. (a) Transient response of the SBC2-based sensor during consecutive exposures ranging from 1 to $40 \mathrm{ppm}$ of acetone in dry air at the operating temperature of $150{ }^{\circ} \mathrm{C}$; (b) calibration curve.

HR-STEM experiments were performed using an FEI Titan low-base microscope operated at $300 \mathrm{kV}$ and equipped with an EDS detector, a CESCOR Cs probe corrector, an ultrabright $\mathrm{X}$-FEG electron source, and a monochromator. HR-STEM imaging was performed using $\mathrm{HAADF}$ and $\mathrm{ADF}$ detectors. The
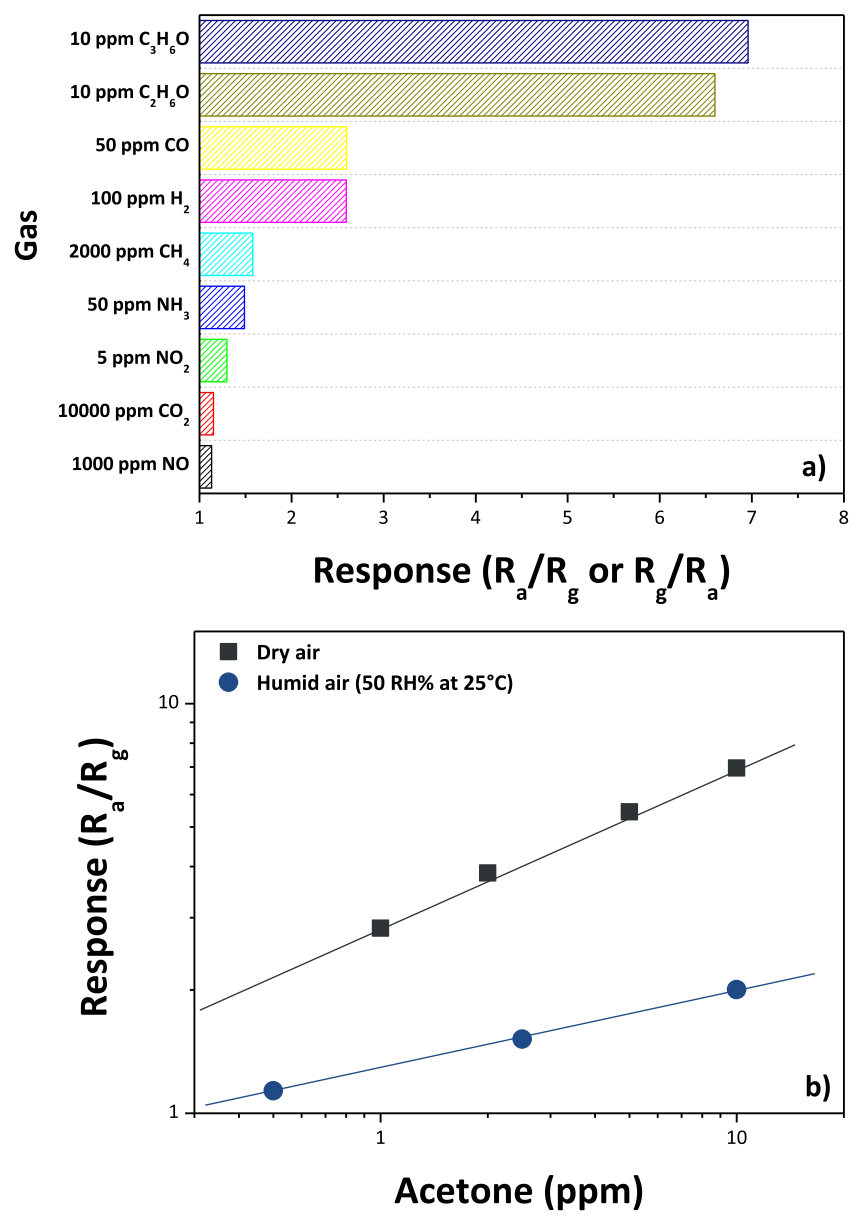

Figure 13. (a) Gas responses of the SBC2-based sensor toward common reducing and oxidizing gases in dry air, operating at $150{ }^{\circ} \mathrm{C}$; (b) comparison of SBC2-based sensor responses toward different concentrations of acetone in dry and humid air $\left(50 \mathrm{RH} \%\right.$ at $\left.25^{\circ} \mathrm{C}\right)$ at the operating temperature of $150{ }^{\circ} \mathrm{C}$.

inner and outer angles for most of the micrographs recorded with the HAADF and ADF detector were 48 and $200 \mathrm{mrad}$ and 22 and $120 \mathrm{mrad}$, respectively. Automatic indexation of the FFT patterns was performed by using the JEMS software. ${ }^{58}$ For TEM studies, samples were dispersed in ethanol in an ultrasound bath for a few minutes and a drop of the suspension was placed onto a molybdenum/nickel grids coated with carbon membrane.

Optical properties of the specimens were investigated by means of DRS on a Shimadzu UV-3100 spectrometer (JP), equipped with an integrating sphere, and a white reference material made of Spectralon; the UV-Vis spectral range $(250-850 \mathrm{~nm})$ was investigated, with $0.2 \mathrm{~nm}$ in resolution. To explore the photochromic properties of the specimens, they were exposed $(0.1 \mathrm{~g})$, for different irradiation times, to either UV-A or visible light. A protocol described in more detail in our previous works ${ }^{10,11,31}$ was severely followed to get comparable data. The UV-A and visible-light lamps were placed above (vertically) the specimen, adjusting the distance between the lamp and the specimen to get the desired irradiance values. The intensity of the radiation reaching the samples, measured with a radiometer (Delta OHM, HD2302.0, IT), was estimated to be $\sim 22 \mathrm{~W} \mathrm{~m}^{-2}$ in the UVA range ( 315 $\mathrm{nm}<\lambda<400 \mathrm{~nm})$ and $\sim 50 \mathrm{~W} \mathrm{~m}^{-2}$ in the visible region $(\lambda>$ $400 \mathrm{~nm}$, being nil in the UVA); irradiation times were 
considered to be consecutive and absolute. Reflectance data were transformed into pseudo-absorption spectra $F(R)$ by means of the Kubelka-Munk transformation: ${ }^{59} F(R)=\alpha=(1$ $-R)^{2} / 2 R$, where $R$ is the reflectance. To explore the reversibility of the photochromic process, fresh un-irradiated samples were exposed to visible light (as above) for periods ranging from 10 to $30 \mathrm{~s}$, at room temperature, and their DRS spectra were recorded immediately. They were then placed in a dark oven at $100{ }^{\circ} \mathrm{C}$ for $15 \mathrm{~min}$ to reverse the process, and the optical spectra were measured again. The degree of photoswitching has been described as the difference between the maximum value in reflectance at time zero $\left(R_{0}\right)$ and the reflectance after each irradiation/annealing cycle $\left(R_{t}\right): \Delta R_{t}(\%)$ $=\left(R_{0}-R_{t}\right) / R_{0} \times 100$. Raman spectra were measured using a RFS 100/S (Bruker, DE) equipped with a $1064 \mathrm{~nm} \mathrm{Nd:YAG}$ laser as the excitation source, in the $50-1000 \mathrm{~cm}^{-1}$ wavenumber range, with $2 \mathrm{~cm}^{-1}$ resolution.

4.3. Gas Sensing. Gas-sensing performance of the synthesized materials was investigated by fabricating resistive gas sensor devices. The screen printing method has been used to make reproducible thick films $\left(3 \times 3 \mathrm{~mm}^{2}\right.$ area, and $\sim 10$ $\mu \mathrm{m}$ in thickness). The synthesized nanopowders were mixed with an appropriate volume of double distilled water to obtain a paste. Appropriate water amounts have been added to have an ink paste with suitable rheological properties. Then, the ink has been deposited by means of a hand screen printer over the interdigitated area of the sensor. This latter was made of an alumina substrates $\left(6 \times 3 \mathrm{~mm}^{2} \times 0.5 \mathrm{~mm}\right)$, supplied by a pair of Pt interdigitated electrodes on one side and a Pt heater on the other side. The film has been printed with the appropriate geometric characteristic by using a proper plastic mask.

Sensing measurements were carried out in the range of temperature $100-400{ }^{\circ} \mathrm{C}$ under a controlled atmosphere, by placing the sensors in an optimized stainless steel test chamber where a constant gas steam of $100 \mathrm{scc} / \mathrm{min}$ was allowed to flow. All gases and acetone vapor (coming from certified bottles) can be progressively diluted in air using mass flow controllers, in order to obtain the desired working concentrations. Electrical resistance of the sensitive films was recorded by a Keithley 6487 picoammeter/voltage source, while an Agilent 3632A was employed to power the heater of the sensor substrate in order to control the operating temperature. The gas sensor response, $S$, is defined as the ratio $R_{\text {air }} / R_{\mathrm{g}}$, where $R_{\text {air }}$ is the electrical resistance of the sensor in reference air (baseline resistance) and $R_{\mathrm{g}}$ is the electrical resistance at the fixed target gas concentration. The response and recovery times, unless otherwise indicated, were calculated at $90 \%$ of response variation.

\section{ASSOCIATED CONTENT}

\section{S Supporting Information}

The Supporting Information is available free of charge on the ACS Publications website at DOI: 10.1021/acsomega.8b01508.

Graphic output of the Rietveld refinement of the sample SBC1; graphic output of the WPPM modeling of SBC1; HR-STEM-HAADF micrographs (samples Ti450 and SBC10); DRS spectra of irradiated samples (UV-A and visible light); Raman spectra before and after UV-A irradiation; response time at $90 \%$ signal variation as a function of temperature (Ti450- and SBC2-based sensors); recovery times of Ti450- and SBC2-based sensors; reproducibility of the SBC2-based sensor; and position and full width half-maximum of Raman $E_{\mathrm{g}}$ mode of anatase (PDF)

\section{AUTHOR INFORMATION}

\section{Corresponding Author}

*E-mail: david.tobaldi@ua.pt and david@davidtobaldi.org. Phone: +351 234370041 .

ORCID

David Maria Tobaldi: 0000-0002-0112-8570

Raul Arenal: 0000-0002-2071-9093

\section{Present Addresses}

\#Departamento de Ciencia de los Materiales e Ingeniería Metalúrgica y Química Inorgánica, Facultad de Ciencias, Universidad de Cádiz, Campus Río San Pedro S/N, Puerto Real 11510, Cádiz, Spain.

"I Instituto Universitario de Investigación de Microscopía Electrónica y Materiales (IMEYMAT), Facultad de Ciencias, Universidad de Cádiz, Campus Río San Pedro S/N, Puerto Real 11510, Cádiz, Spain.

\section{Notes}

The authors declare no competing financial interest.

\section{ACKNOWLEDGMENTS}

This work was developed within the scope of the project CICECO-Aveiro Institute of Materials, POCI-01-0145FEDER-007679 (FCT Ref. UID/CTM/50011/2013), financed by national funds through the FCT/MEC and when appropriate co-financed by FEDER under the PT2020 Partnership Agreement. The STEM measurements were performed in the Laboratorio de Microscopias Avanzadas (LMA) at the Instituto de Nanociencia de Aragon (INA)Universidad de Zaragoza (Spain). R.A. gratefully acknowledges the support from the Spanish Ministerio de Economia y Competitividad (MAT2016-79776-P), from the Government of Aragon, and the European Social Fund under the project "Construyendo Europa desde Aragon" 2014-2020 (grant number E/26).

\section{REFERENCES}

(1) Key attributes of nano-scale materials and functionalities emerging from them. In Nanoscale Multifunctional Materials: Science and Applications; Mukhopadhyay, S. M., Ed.; John Wiley \& Sons, Inc.: Hoboken, NJ, USA, 2011; pp 3-33.

(2) Zhang, J. Z. Understanding the Growth of Metal Oxide Nanostructures. J. Phys. Chem. Lett. 2012, 3, 2920-2921.

(3) Bai, Y.; Mora-Seró, I.; De Angelis, F.; Bisquert, J.; Wang, P. Titanium Dioxide Nanomaterials for Photovoltaic Applications. Chem. Rev. 2014, 114, 10095-10130.

(4) Fujishima, A.; Honda, K. Electrochemical Photolysis of Water at a Semiconductor Electrode. Nature 1972, 238, 37-38.

(5) Kamat, P. V. A Conversation with Akira Fujishima. ACS Energy Lett. 2017, 2, 1586-1587.

(6) Fujishima, A.; Rao, T. N.; Tryk, D. A. Titanium Dioxide Photocatalysis. J. Photochem. Photobiol., C 2000, 1, 1-21.

(7) Tobaldi, D. M.; Piccirillo, C.; Pullar, R. C.; Gualtieri, A. F.; Seabra, M. P.; Castro, P. M. L.; Labrincha, J. A. Silver-Modified NanoTitania as an Antibacterial Agent and Photocatalyst. J. Phys. Chem. C 2014, 118, 4751-4766.

(8) Ohko, Y.; Tatsuma, T.; Fujii, T.; Naoi, K.; Niwa, C.; Kubota, Y.; Fujishima, A. Multicolour Photochromism of TiO2 Films Loaded with Silver Nanoparticles. Nat. Mater. 2002, 2, 29-31.

(9) Kafizas, A.; Dunnill, C. W.; Parkin, I. P. The Relationship between Photocatalytic Activity and Photochromic State of Nano- 
particulate Silver Surface Loaded Titanium Dioxide Thin-Films. Phys. Chem. Chem. Phys. 2011, 13, 13827.

(10) Tobaldi, D. M.; Hortigüela Gallo, M. J.; Otero-Irurueta, G.; Singh, M. K.; Pullar, R. C.; Seabra, M. P.; Labrincha, J. A. Purely Visible-Light-Induced Photochromism in $\mathrm{Ag}-\mathrm{TiO} 2$ Nanoheterostructures. Langmuir 2017, 33, 4890-4902.

(11) Tobaldi, D. M.; Rozman, N.; Leoni, M.; Seabra, M. P.; Škapin, A. S.; Pullar, R. C.; Labrincha, J. A. Cu-TiO2 Hybrid Nanoparticles Exhibiting Tunable Photochromic Behavior. J. Phys. Chem. C 2015, 119, 23658-23668.

(12) Parola, S.; Julián-López, B.; Carlos, L. D.; Sanchez, C. Optical Properties of Hybrid Organic-Inorganic Materials and Their Applications. Adv. Funct. Mater. 2016, 26, 6506-6544.

(13) Mirzaei, A.; Leonardi, S. G.; Neri, G. Detection of Hazardous Volatile Organic Compounds (VOCs) by Metal Oxide Nanostructures-Based Gas Sensors: A Review. Ceram. Int. 2016, 42, 1511915141.

(14) Barreca, D.; Carraro, G.; Comini, E.; Gasparotto, A.; Maccato, C.; Sada, C.; Sberveglieri, G.; Tondello, E. Novel Synthesis and Gas Sensing Performances of $\mathrm{CuO}-\mathrm{TiO} 2$ Nanocomposites Functionalized with Au Nanoparticles. J. Phys. Chem. C 2011, 115, 10510-10517.

(15) Zakrzewska, K. Gas Sensing Mechanism of TiO2-Based Thin Films. Vacuum 2004, 74, 335-338.

(16) Lou, Z.; Li, F.; Deng, J.; Wang, L.; Zhang, T. Branch-like Hierarchical Heterostructure $(\alpha-\mathrm{Fe} 2 \mathrm{O} 3 / \mathrm{TiO} 2)$ : A Novel Sensing Material for Trimethylamine Gas Sensor. ACS Appl. Mater. Interfaces 2013, 5, 12310-12316.

(17) Murakami, R. 7-Japanese Traditional Alloys. In Metal Plating and Patination; Niece, S. L., Craddock, P., Eds.; ButterworthHeinemann, 1993; pp 85-94.

(18) Kubacka, A.; Muñoz-Batista, M. J.; Ferrer, M.; FernándezGarcía, M. UV and Visible Light Optimization of Anatase TiO2 Antimicrobial Properties: Surface Deposition of Metal and Oxide (Cu, Zn, Ag) Species. Appl. Catal., B 2013, 140-141, 680-690.

(19) Méndez-Medrano, M. G.; Kowalska, E.; Lehoux, A.; Herissan, A.; Ohtani, B.; Bahena, D.; Briois, V.; Colbeau-Justin, C.; RodríguezLópez, J. L.; Remita, H. Surface Modification of $\mathrm{TiO} 2$ with $\mathrm{Ag}$ Nanoparticles and $\mathrm{CuO}$ Nanoclusters for Application in Photocatalysis. J. Phys. Chem. C 2016, 120, 5143-5154.

(20) Pottier, A.; Chanéac, C.; Tronc, E.; Mazerolles, L.; Jolivet, J.-P. Synthesis of Brookite TiO2 Nanoparticles by Thermolysis of TiCl4 in Strongly Acidic Aqueous Media. J. Mater. Chem. 2001, 11, 11161121.

(21) Casotti, D.; Ardit, M.; Dinnebier, R.; Dondi, M.; Matteucci, F.; Zama, I.; Cruciani, G. Limited Crystallite Growth upon Isothermal Annealing of Nanocrystalline Anatase. Cryst. Growth Des. 2015, 15, 2282-2290.

(22) Shannon, R. D.; Pask, J. A. Kinetics of the Anatase-Rutile Transformation. J. Am. Ceram. Soc. 1965, 48, 391-398.

(23) Shannon, R. D. Revised Effective Ionic Radii and Systematic Studies of Interatomic Distances in Halides and Chalcogenides. Acta Crystallogr., Sect. A: Cryst. Phys., Diffr., Theor. Gen. Crystallogr. 1976, 32, 751-767.

(24) Li Bassi, A.; Cattaneo, D.; Russo, V.; Bottani, C. E.; Barborini, E.; Mazza, T.; Piseri, P.; Milani, P.; Ernst, F. O.; Wegner, K.; et al. Raman Spectroscopy Characterization of Titania Nanoparticles Produced by Flame Pyrolysis: The Influence of Size and Stoichiometry. J. Appl. Phys. 2005, 98, 074305.

(25) Karmaoui, M.; Amaral, J. S.; Lajaunie, L.; Puliyalil, H.; Tobaldi, D. M.; Pullar, R. C.; Labrincha, J. A.; Arenal, R.; Cvelbar, U. Smallest Bimetallic CoPt3 Superparamagnetic Nanoparticles. J. Phys. Chem. Lett. 2016, 7, 4039-4046.

(26) Burns, R. G. Crystal field spectra of transition metal ions in minerals. In Mineralogical Applications of Crystal Field Theory, 2nd ed.; Burns, R. G., Ed.; Cambridge University Press, 1993; pp 1-576.

(27) Irie, H.; Miura, S.; Kamiya, K.; Hashimoto, K. Efficient Visible Light-Sensitive Photocatalysts: Grafting $\mathrm{Cu}(\mathrm{II})$ Ions onto $\mathrm{TiO} 2$ and WO3 Photocatalysts. Chem. Phys. Lett. 2008, 457, 202-205.
(28) Irie, H.; Kamiya, K.; Shibanuma, T.; Miura, S.; Tryk, D. A.; Yokoyama, T.; Hashimoto, K. Visible Light-Sensitive $\mathrm{Cu}(\mathrm{II})$-Grafted TiO2 Photocatalysts: Activities and X-ray Absorption Fine Structure Analyses. J. Phys. Chem. C 2009, 113, 10761-10766.

(29) Banerjee, S.; Chakravorty, D. Optical absorption by nanoparticles of Cu2O. Europhys. Lett. 2000, 52, 468-473.

(30) Qiu, X.; Miyauchi, M.; Sunada, K.; Minoshima, M.; Liu, M.; Lu, Y.; Li, D.; Shimodaira, Y.; Hosogi, Y.; Kuroda, Y.; et al. Hybrid $\mathrm{CuxO} / \mathrm{TiO} 2$ Nanocomposites As Risk-Reduction Materials in Indoor Environments. ACS Nano 2012, 6, 1609-1618.

(31) Tobaldi, D. M.; Leonardi, S. G.; Pullar, R. C.; Seabra, M. P.; Neri, G.; Labrincha, J. A. Sensing properties and photochromism of Ag-TiO2 nano-heterostructures. J. Mater. Chem. A 2016, 4, 96009613.

(32) Fateixa, S.; Nogueira, H. I. S.; Trindade, T. Hybrid Nanostructures for SERS: Materials Development and Chemical Detection. Phys. Chem. Chem. Phys. 2015, 17, 21046-21071.

(33) Xu, Y.; Schoonen, M. A. A. The Absolute Energy Positions of Conduction and Valence Bands of Selected Semiconducting Minerals. Am. Mineral. 2000, 85, 543-556.

(34) Wang, B.; Durantini, J.; Nie, J.; Lanterna, A. E.; Scaiano, J. C. Heterogeneous Photocatalytic Click Chemistry. J. Am. Chem. Soc. 2016, 138, 13127-13130.

(35) Zhang, J.; Zou, Q.; Tian, H. Photochromic Materials: More Than Meets The Eye. Adv. Mater. 2013, 25, 378-399.

(36) Kimmel, G. A.; Petrik, N. G. Tetraoxygen on Reduced TiO 2 ( 110 ): Oxygen Adsorption and Reactions with Bridging Oxygen Vacancies. Phys. Rev. Lett. 2008, 100, 196102.

(37) Zeng, W.; Liu, T.; Wang, Z.; Tsukimoto, S.; Saito, M.; Ikuhara, Y. Oxygen Adsorption on Anatase $\mathrm{TiO}_{2}$ (101) and (001) Surfaces from First Principles. Mater. Trans. 2010, 51, 171-175.

(38) Mondal, B.; Basumatari, B.; Das, J.; Roychaudhury, C.; Saha, H.; Mukherjee, N. ZnO-SnO2 based composite type gas sensor for selective hydrogen sensing. Sens. Actuators, B 2014, 194, 389-396.

(39) Liang, Y. Q.; Cui, Z. D.; Zhu, S. L.; Li, Z. Y.; Yang, X. J.; Chen, Y. J.; Ma, J. M. Design of a Highly Sensitive Ethanol Sensor Using a Nano-Coaxial p-Co3O4/n-TiO2 Heterojunction Synthesized at Low Temperature. Nanoscale 2013, 5, 10916.

(40) Dutta, P. K.; Ginwalla, A.; Hogg, B.; Patton, B. R.; Chwieroth, B.; Liang, Z.; Gouma, P.; Mills, M.; Akbar, S. Interaction of Carbon Monoxide with Anatase Surfaces at High Temperatures: Optimization of a Carbon Monoxide Sensor. J. Phys. Chem. B 1999, 103, 44124422.

(41) Phanichphant, S.; Liewhiran, C.; Wetchakun, K.; Wisitsoraat, A.; Tuantranont, A. Flame-Made Nb-Doped TiO2 Ethanol and Acetone Sensors. Sensors 2011, 11, 472-484.

(42) Yadava, L.; Verma, R.; Singh, R. S. Detection and Sensing Mechanism of Acetone with Modeling Using Pd/TiO2/Si Structure. Thin Solid Films 2012, 520, 3039-3042.

(43) Zakrzewska, K.; Radecka, M. TiO2-Based Nanomaterials for Gas Sensing-Influence of Anatase and Rutile Contributions. Nanoscale Res. Lett. 2017, 12, 89.

(44) Teleki, A.; Pratsinis, S. E.; Kalyanasundaram, K.; Gouma, P. I. Sensing of Organic Vapors by Flame-Made TiO2 Nanoparticles. Sens. Actuators, B 2006, 119, 683-690.

(45) Teleki, A.; Bjelobrk, N.; Pratsinis, S. Flame-Made Nb- and CuDoped TiO2 Sensors for CO and Ethanol. Sens. Actuators, B 2008, $130,449-457$.

(46) Savage, N.; Chwieroth, B.; Ginwalla, A.; Patton, B. R.; Akbar, S. A.; Dutta, P. K. Composite n-p semiconducting titanium oxides as gas sensors. Sens. Actuators, B 2001, 79, 17-27.

(47) Navale, S. T.; Yang, Z. B.; Liu, C.; Cao, P. J.; Patil, V. B.; Ramgir, N. S.; Mane, R. S.; Stadler, F. J. Enhanced Acetone Sensing Properties of Titanium Dioxide Nanoparticles with a Sub-Ppm Detection Limit. Sens. Actuators, B 2018, 255, 1701-1710.

(48) Konvalina, G.; Haick, H. Effect of Humidity on NanoparticleBased Chemiresistors: A Comparison between Synthetic and RealWorld Samples. ACS Appl. Mater. Interfaces 2012, 4, 317-325. 
(49) Tobaldi, D. M.; Pullar, R. C.; Gualtieri, A. F.; Seabra, M. P.; Labrincha, J. A. Sol-gel synthesis, characterisation and photocatalytic activity of pure, $\mathrm{W}-, \mathrm{Ag}$ - and $\mathrm{W} / \mathrm{Ag}$ co-doped $\mathrm{TiO} 2$ nanopowders. Chem. Eng. J. 2013, 214, 364-375.

(50) Larson, A. C.; Von Dreele, R. B. General Structure Analysis System (GSAS); Los Alamos National Laboratory Report LAUR, 2004.

(51) Toby, B. H. EXPGUI, a graphical user interface forGSAS. J. Appl. Crystallogr. 2001, 34, 210-213.

(52) Howard, C. J.; Sabine, T. M.; Dickson, F. Structural and Thermal Parameters for Rutile and Anatase. Acta Crystallogr., Sect. B: Struct. Sci. 1991, 47, 462-468.

(53) Meagher, E. P.; Lager, G. A. Polyhedral Thermal Expansion in the TiO2 Polymorphs; Refinement of the Crystal Structures of Rutile and Brookite at High Temperature. Can. Mineral. 1979, 17, 77-85.

(54) Tobaldi, D. M.; Pullar, R. C.; Gualtieri, A. F.; Seabra, M. P.; Labrincha, J. A. Phase Composition, Crystal Structure and Microstructure of Silver and Tungsten Doped TiO2 Nanopowders with Tuneable Photochromic Behaviour. Acta Mater. 2013, 61, 55715585.

(55) Scardi, P.; Ortolani, M.; Leoni, M. WPPM: Microstructural Analysis beyond the Rietveld Method. Mater. Sci. Forum 2010, 651, 155-171.

(56) Leoni, M.; Confente, T.; Scardi, P. PM2K: A Flexible Program Implementing Whole Powder Pattern Modelling. Z. Kristallogr. Suppl. 2006, 2006, 249-254.

(57) Caglioti, G.; Paoletti, A.; Ricci, F. P. On Resolution and Luminosity of a Neutron Diffraction Spectrometer for Single Crystal Analysis. Nucl. Instrum. Methods 1960, 9, 195-198.

(58) Stadelmann, P. JEMS-SAAS, 2014.

(59) Marfunin, A. S. Atomic Spectroscopy and Spectrochemical Analysis of Minerals, Rocks, and Ores; Spectroscopy-Cosmochemistry-Astrophysics. In Physics of Minerals and Inorganic Materials: An Introduction; Egorova, N. G., Mishchenko, A. G., Eds.; SpringerVerlag: Berlin, 1979; pp 1-342. 